\title{
CO measurements from the ACE-FTS satellite instrument: data analysis and validation using ground-based, airborne and spaceborne observations
}

C. Clerbaux ${ }^{1}$, M. George ${ }^{1}$, S. Turquety ${ }^{1}$, K. A. Walker ${ }^{2,3}$, B. Barret ${ }^{4}$, P. Bernath ${ }^{2,5}$, C. Boone ${ }^{2}$, T. Borsdorff ${ }^{6}$, J. P. Cammas ${ }^{4}$, V. Catoire ${ }^{7}$, M. Coffey ${ }^{8}$, P.-F. Coheur ${ }^{9}$, M. Deeter ${ }^{8}$, M. De Mazière ${ }^{10}$, J. Drummond ${ }^{11}$, P. Duchatelet ${ }^{12}$, E. Dupuy ${ }^{2}$, R. de Zafra ${ }^{13}$, F. Eddounia ${ }^{1}$, D. P. Edwards ${ }^{8}$, L. Emmons ${ }^{8}$, B. Funke ${ }^{14}$, J. Gille ${ }^{8}$, D. W. T. Griffith ${ }^{15}$, J. Hannigan ${ }^{8}$, F. Hase ${ }^{16}$, M. Höpfner ${ }^{16}$, N. Jones ${ }^{15}$, A. Kagawa ${ }^{17}$, Y. Kasai ${ }^{18}$, I. Kramer ${ }^{16}$, E. Le Flochmoën ${ }^{4}$, N. J. Livesey ${ }^{19}$, M. López-Puertas ${ }^{14}$, M. Luo ${ }^{20}$, E. Mahieu ${ }^{12}$, D. Murtagh ${ }^{21}$, P. Nédélec ${ }^{4}$, A. Pazmino ${ }^{1}$, H. Pumphrey ${ }^{22}$, P. Ricaud ${ }^{4}$, C. P. Rinsland ${ }^{23}$, C. Robert $^{7}$, M. Schneider ${ }^{16}$, C. Senten ${ }^{10}$, G. Stiller ${ }^{16}$, A. Strandberg ${ }^{21}$, K. Strong ${ }^{3}$, R. Sussmann ${ }^{6}$, V. Thouret $^{4}$, J. Urban ${ }^{21}$, and A. Wiacek ${ }^{3}$

${ }^{1}$ Université Paris 6, CNRS, Service d'Aéronomie/IPSL, Paris, France

${ }^{2}$ Department of Chemistry, University of Waterloo, Waterloo, Ontario, Canada N2L 3G1, Canada

${ }^{3}$ Department of Physics, University of Toronto, Toronto, Ontario, Canada M5S 1A7, Canada

${ }^{4}$ Laboratoire d'Aérologie UMR 5560, Observatoire Midi-Pyrénées, Toulouse, France

${ }^{5}$ Department of Chemistry, University of York, Heslington, York YO10 5DD, UK

${ }^{6}$ Forschungszentrum Karlsruhe, IMK-IFU, Garmisch-Partenkirchen, Germany

${ }^{7}$ Laboratoire de Physique et Chimie de l'Environnement, CNRS, Université d'Orléans, Orléans, France

${ }^{8}$ National Center for Atmospheric Research, Boulder, CO, USA

${ }^{9}$ Spectroscopie de l'atmosphère, Chimie Quantique et Photophysique, Université Libre de Bruxelles (U.L.B.), Brussels, Belgium. P.-F. Coheur is Research associate with the FRS-F.N.R.S, Belgium

${ }^{10}$ Belgian Institute for Space Aeronomy, Brussels, Belgium

${ }^{11}$ Department of Physics \& Atmospheric Science, Dalhousie University, Halifax, Canada

${ }^{12}$ Université de Liège ULg, Institute of Astrophysics and Geophysics, Liège, Belgium

${ }^{13}$ Department of Physics and Astronomy, State Univ. of New York at Stony Brook, USA

${ }^{14}$ Instituto de Astrofísica, Andalucía (CSIC), Granada, Spain

${ }^{15}$ Department of Chemistry, University of Wollongong, Wollongong, New South Wales, Australia

${ }^{16}$ Institut für Meteorologie und Klimaforschung, Forschungszentrum Karlsruhe, Germany

${ }^{17}$ Fujitsu FIP Corporation, Tokyo, Japan

${ }^{18}$ National Institute of Information and Communications Technology, Tokyo, Japan

${ }^{19}$ Microwave Atmospheric Science Team, Jet Propulsion Laboratory, CA, USA

${ }^{20}$ Jet Propulsion Laboratory, California Institute of Technology, Pasadena, California, USA

${ }^{21}$ Chalmers University of Technology, Göteborg, Sweden

${ }^{22}$ School of GeoSciences, Edinburgh, Scotland

${ }^{23}$ NASA Langley Research Center, Hampton, Virginia, USA

Received: 19 September 2007 - Published in Atmos. Chem. Phys. Discuss.: 30 October 2007

Revised: 6 May 2008 - Accepted: 6 May 2008 - Published: 16 May 2008

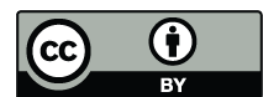

Correspondence to: C. Clerbaux

(ccl@aero.jussieu.fr)

Published by Copernicus Publications on behalf of the European Geosciences Union. 


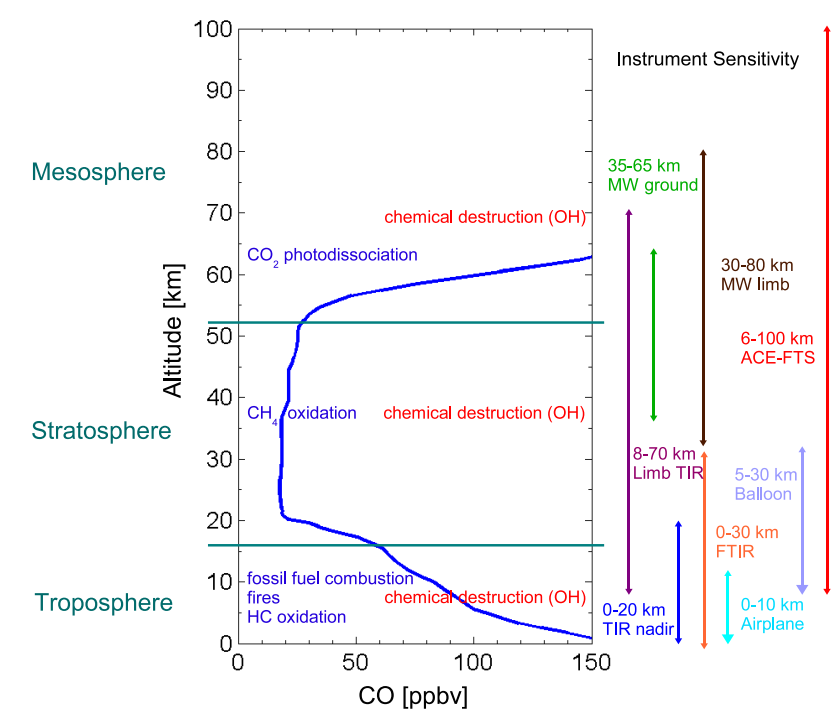

Fig. 1. Schematic plot of a standard atmospheric CO profile, with the different sources of production (blue) and destruction/sinks (red) as a function of altitude. The CO profile was constructed from averaged ACE-FTS data over China and completed with TES data over the same area below $6 \mathrm{~km}$. The vertical sensitivity of each $\mathrm{CO}$ sounding type of instrument is also reported on the right-hand side of this plot. MW and TIR refer to millimeter-wave and thermal infrared spectral regions, respectively.

Abstract. The Atmospheric Chemistry Experiment (ACE) mission was launched in August 2003 to sound the atmosphere by solar occultation. Carbon monoxide (CO), a good tracer of pollution plumes and atmospheric dynamics, is one of the key species provided by the primary instrument, the ACE-Fourier Transform Spectrometer (ACE-FTS). This instrument performs measurements in both the CO 1-0 and 2-0 ro-vibrational bands, from which vertically resolved $\mathrm{CO}$ concentration profiles are retrieved, from the mid-troposphere to the thermosphere. This paper presents an updated description of the ACE-FTS version 2.2 CO data product, along with a comprehensive validation of these profiles using available observations (February 2004 to December 2006). We have compared the CO partial columns with ground-based measurements using Fourier transform infrared spectroscopy and millimeter wave radiometry, and the volume mixing ratio profiles with airborne (both high-altitude balloon flight and airplane) observations. CO satellite observations provided by nadir-looking instruments (MOPITT and TES) as well as limb-viewing remote sensors (MIPAS, SMR and MLS) were also compared with the ACE-FTS CO products. We show that the ACE-FTS measurements provide CO profiles with small retrieval errors (better than 5\% from the upper troposphere to $40 \mathrm{~km}$, and better than $10 \%$ above). These observations agree well with the correlative measurements, considering the rather loose coincidence criteria in some cases. Based on the validation exercise we assess the following uncertain- ties to the ACE-FTS measurement data: better than $15 \%$ in the upper troposphere $(8-12 \mathrm{~km})$, than $30 \%$ in the lower stratosphere $(12-30 \mathrm{~km})$, and than $25 \%$ from 30 to $100 \mathrm{~km}$.

\section{Introduction}

Carbon monoxide (CO) plays an important role in atmospheric chemistry and is one of the key species that needs to be measured globally and at different altitudes. The primary emission sources of $\mathrm{CO}$ are associated with combustion processes (transport, heating, industrial activities and biomass burning), along with biogenic sources and oceans. It is also produced from the oxidation of methane and non-methane hydrocarbons (see Fig. 1). At surface level, the volume mixing ratios range from a background concentration of 50 parts per billion by volume (ppbv) to excess of $700 \mathrm{ppbv}$ where high emissions occur. Large uncertainties remain in the estimated strengths of both natural and anthropogenic sources. The main sink for $\mathrm{CO}$ is chemical destruction by reaction with the hydroxyl radical $(\mathrm{OH})$. In the lower atmosphere, where $\mathrm{CO}$ has a lifetime of several weeks to a few months, its observation allows the characterization of both emission sources and atmospheric transport of pollution plumes (Logan, 1981). In the upper troposphere, CO can also be transported across the tropical tropopause. In the stratosphere, $\mathrm{CO}$ is produced by the oxidation of methane and is converted to carbon dioxide $\left(\mathrm{CO}_{2}\right)$ by reaction with $\mathrm{OH}$. Above $50 \mathrm{~km}$, in the mesosphere and thermosphere, photolysis of $\mathrm{CO}_{2}$ is the main source of $\mathrm{CO}$, which reaches a concentration of 520 parts per million by volume (ppmv) at $80 \mathrm{~km}$. At these altitudes, $\mathrm{CO}$ is also a useful dynamical tracer which can be used to study atmospheric transport processes, and, in particular, upward transport in high latitude summer regions and downward transport in the high latitude winter regions (e.g. Solomon et al., 1985).

Several remote sensing and in situ techniques provide routine measurements to monitor the spatial and temporal changes in the concentration of atmospheric $\mathrm{CO}$. The accuracy, sampling and vertical, horizontal and temporal coverage of these measurements depend on the instrument and the observation technique (e.g. ground-based, airborne, or satellite-borne) and, in the case of optical measurements, of the spectral range and resolution used. Ground-based remote sensing techniques, in particular those available from the numerous sites in the Network for the Detection of Atmospheric Composition Change (NDACC, formerly NDSC, see http://www.ndacc.org) that are equipped with Fourier Transform Infrared (FTIR) instruments, have provided long-term CO atmospheric measurements (Kurylo, 1991; Yurganov et al., 2004; 2005; Velazco et al., 2007). Airborne MOZAIC (Measurements of OZone aboard in-service AIrbus airCraft) flights provide routine monitoring of $\mathrm{CO}$ in the upper troposphere over large areas (Nedelec et al., 2005). Currently there 


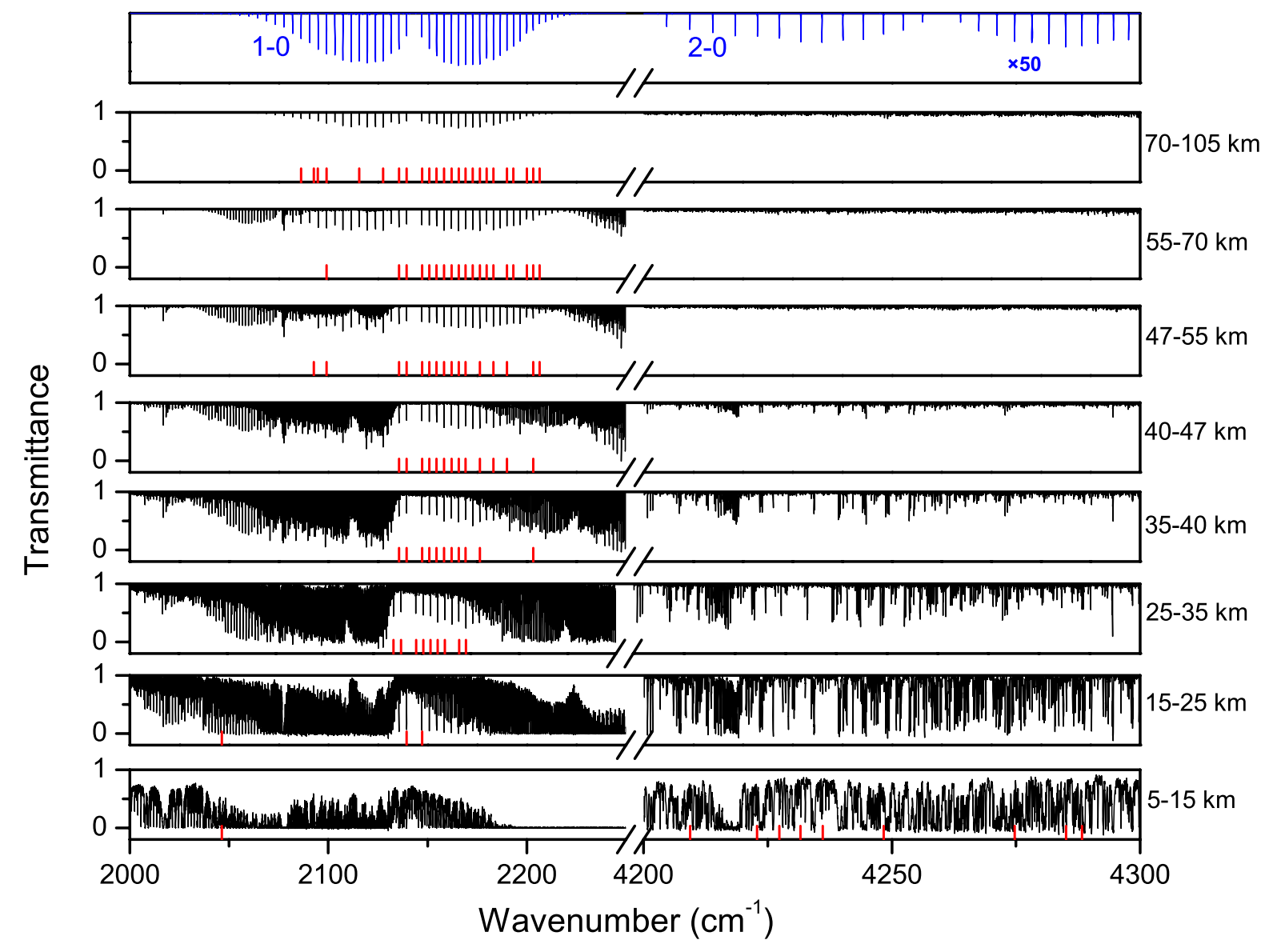

Fig. 2. Microwindows (version 2.2., red lines) used to retrieve CO vertical profiles from the ACE-FTS spectra, for a typical occultation sequence spanning from the free troposphere to the mesosphere. The numbers on the right give the approximate altitude range where the microwindows are valid. The top panel shows a simulated $\mathrm{CO}$ spectrum (blue), with the absorption in the 2-0 band multiplied by a factor of 50 for clarity.

are extensive $\mathrm{CO}$ observations from space from several nadir looking remote sensors, such as MOPITT/Terra (Edwards et al., 2004; Clerbaux et al., 2008), SCIAMACHY/Envisat (Frankenberg et al., 2005), TES/Aura (Rinsland et al., 2006a; Luo et al., 2007a), and the recently launched IASI/Metop (Turquety et al., 2004; Clerbaux et al., 2007), which are yielding a global view of the $\mathrm{CO}$ tropospheric distribution. Although some of them (TES, SCIAMACHY) are also able to partly sound the atmosphere using a limb geometry, their ability to retrieve vertical information is limited. From space, vertically resolved profiles can be derived from measurements using limb geometry, in emission or absorption. The currently available limb-sounders working in emission are SCIAMACHY, MIPAS/Envisat (Funke et al., 2007), which uses the mid-infrared spectral range, SMR/Odin (Murtagh et al., 2002) and MLS/Aura (Pumphrey et al., 2007), which both rely on millimeter-wave spectroscopy. In absorption the single instrument currently providing $\mathrm{CO}$ measurements is the infrared Atmospheric Chemistry Experiment Fourier
Transform Spectrometer (ACE-FTS) (Bernath et al., 2005). It is worth noting that, among these instruments, only the ACE-FTS is capable of sounding CO simultaneously from the mid-troposphere to the mesosphere.

Intercomparison experiments are needed to validate the $\mathrm{CO}$ products obtained by different remote sounding instruments (Clerbaux et al., 2002; Emmons et al., 2004; Jin et al., 2005; Sussmann and Buchwitz, 2005; Dils et al., 2006; Barret et al., 2006; Luo et al., 2007a; Pumphrey et al., 2007; Warner et al., 2007; Rinsland et al., 2008). As the ACE mission approached its first public data release, a comprehensive exercise was undertaken to validate the retrieved profiles with the other datasets available. This paper aims at validating $\mathrm{CO}$ partial columns and profiles with correlative independent measurements. The paper is organized as follows: First, we describe the ACE mission, the ACE-FTS instrument and the $\mathrm{CO}$ version 2.2 (v2.2) data product from the ACE-FTS. Second, the co-located observations provided by different ground-based, balloon, airborne and satellite 
Table 1. Microwindows used for the ACE-FTS CO (main isotopologue) version 2.2 retrievals.

\begin{tabular}{|c|c|c|c|}
\hline Center wavenumber $\left(\mathrm{cm}^{-1}\right)$ & Microwindow width $\left(\mathrm{cm}^{-1}\right)$ & Lower altitude $(\mathrm{km})$ & Upper altitude $(\mathrm{km})$ \\
\hline $1119.20^{(a)}$ & 0.38 & 35 & 47 \\
\hline $1121.45^{(a)}$ & 0.35 & 5 & 35 \\
\hline 2046.29 & 0.24 & 8 & 25 \\
\hline 2086.37 & 0.40 & 70 & 105 \\
\hline 2092.71 & 0.40 & 47 & 55 \\
\hline 2094.76 & 0.40 & 70 & 105 \\
\hline 2099.08 & 0.40 & 47 & 105 \\
\hline 2115.63 & 0.35 & 65 & 105 \\
\hline 2127.67 & 0.40 & 70 & 105 \\
\hline 2135.54 & 0.40 & 25 & 105 \\
\hline 2139.40 & 0.40 & 15 & 105 \\
\hline 2147.18 & 0.35 & 15 & 105 \\
\hline 2150.93 & 0.30 & 25 & 105 \\
\hline 2154.55 & 0.26 & 27 & 105 \\
\hline 2158.35 & 0.50 & 28 & 105 \\
\hline 2162.02 & 0.35 & 35 & 105 \\
\hline 2165.64 & 0.30 & 28 & 105 \\
\hline 2169.23 & 0.35 & 30 & 105 \\
\hline 2172.76 & 0.40 & 55 & 105 \\
\hline 2176.35 & 0.30 & 35 & 105 \\
\hline 2179.77 & 0.40 & 60 & 105 \\
\hline 2183.20 & 0.40 & 40 & 105 \\
\hline 2189.93 & 0.35 & 40 & 105 \\
\hline 2193.30 & 0.35 & 55 & 105 \\
\hline 2200.00 & 0.35 & 55 & 105 \\
\hline 2203.19 & 0.35 & 35 & 105 \\
\hline 2206.43 & 0.28 & 45 & 100 \\
\hline $2667.85^{(b)}$ & 0.40 & 5 & 25 \\
\hline 4209.39 & 0.30 & 5 & 15 \\
\hline 4222.88 & 0.40 & 5 & 15 \\
\hline 4227.35 & 0.60 & 5 & 15 \\
\hline 4231.63 & 0.45 & 5 & 15 \\
\hline 4236.05 & 0.45 & 5 & 15 \\
\hline 4248.35 & 0.35 & 5 & 15 \\
\hline 4274.77 & 0.30 & 5 & 15 \\
\hline 4285.12 & 0.50 & 5 & 15 \\
\hline 4288.27 & 0.35 & 7 & 15 \\
\hline
\end{tabular}

(a) Microwindow for interferer $\mathrm{O}_{3}$ : the mixing ratio profiles of this interfering species are fitted simultaneously with the target $\mathrm{CO}$ profile.

(b) Microwindow for interferer $\mathrm{CH}_{4}$ : the mixing ratio profiles of this interfering species are fitted simultaneously with the target $\mathrm{CO}$ profile.

instruments are outlined. Next, we discuss the comparisons between the ACE-FTS CO data and correlative observations available from March 2004 to December 2006, and, finally, we conclude with the reliability of v2.2 ACE-FTS CO data at different latitudes and altitude levels.

\section{CO observations from the ACE-FTS}

\subsection{The ACE mission and the ACE-FTS instrument}

The ACE mission (Bernath et al., 2005) on board the Canadian SCISAT-1 satellite was launched on 12 August 2003. The principal instrument of the mission, known as ACEFTS, is a high resolution $\left(0.02 \mathrm{~cm}^{-1}\right.$, corresponding to a maximum optical path difference of $25 \mathrm{~cm}$ ) infrared Fourier transform spectrometer operating from 2 to 13 microns ( 750 $4400 \mathrm{~cm}^{-1}$ ), that measures the vertical distribution of trace 
Table 2. Estimated total error on the retrieved CO partial columns from the ACE-FTS measurements, along with the relative contribution of the instrumental noise. The latter is the main contributor to the error budget. The other contributions include principally uncertainties in the retrieved temperature profiles (a $1 \mathrm{~K}$ uncertainty on each retrieval altitude was considered) and fitted interfering species.

\begin{tabular}{ccc}
\hline Altitude $(\mathrm{km})$ & Retrieval error (\%) & Instrumental noise contribution (\%) \\
\hline $6-12$ & 1.9 & 60 \\
$12-25$ & 0.5 & 71 \\
$25-50$ & 0.5 & 69 \\
$50-80$ & 1.1 & 98 \\
$80-100$ & 1.1 & 96 \\
\hline
\end{tabular}

gases, pressure, and temperature, by solar occultation. The baseline species retrieved from the v2.2 occultation measurements are $\mathrm{O}_{3}, \mathrm{CH}_{4}, \mathrm{H}_{2} \mathrm{O}, \mathrm{NO}, \mathrm{NO}_{2}, \mathrm{ClONO}_{2}, \mathrm{HNO}_{3}$, $\mathrm{N}_{2} \mathrm{O}, \mathrm{N}_{2} \mathrm{O}_{5}, \mathrm{HCl}, \mathrm{CCl}_{3} \mathrm{~F}, \mathrm{CCl}_{2} \mathrm{~F}_{2}, \mathrm{HF}$, and $\mathrm{CO}$ (Boone et al., 2005). While in orbit, the SCISAT instruments observe up to 15 sunrises and 15 sunsets per day. The vertical sampling is about $3-4 \mathrm{~km}$, on average, from the cloud tops up to about $105 \mathrm{~km}$. Thanks to its excellent signal-to-noise ratio (effective SNR better than 200-300 over much of its spectral range) and $2 \mathrm{~s}$ measurement time, ACE-FTS provides accurate measurements with high vertical sampling, but its horizontal resolution is limited by the $500 \mathrm{~km}$ path length of solar occultation technique.

\subsection{ACE-FTS CO retrievals}

The ACE-FTS CO profiles (Boone et al., 2005) are retrieved by analysing sequences of solar occultation measurements taken during a sunrise or sunset, as seen from the satellite. These analyses take advantage of absorptions in both the fundamental 1-0 $(4.7 \mu \mathrm{m})$ and the overtone 2-0 $(2.3 \mu \mathrm{m}) \mathrm{CO}$ ro-vibration bands (Clerbaux et al., 2005). Because a large range of optical thicknesses is encountered during a sequence of measurements, the $\mathrm{CO}$ retrieval can best be performed using transmittance information from both absorption bands. Figure 2 illustrates the $\mathrm{CO}$ spectra as recorded at different tangent altitudes during one ACE-FTS occultation sequence. At high altitudes ( $>60 \mathrm{~km}$ ), the $\mathrm{CO}$ generated from the $\mathrm{CO}_{2}$ photo-dissociation is the strongest absorber in the $4.7 \mu \mathrm{m}$ spectral range, but the lines saturate at lower tangent heights and the interferences from other atmospheric species $\left(\mathrm{H}_{2} \mathrm{O}\right.$, $\mathrm{O}_{3}, \mathrm{~N}_{2} \mathrm{O}, \mathrm{CO}_{2}$ ) increase. Both the saturation and the interferences prevent an accurate tropospheric $\mathrm{CO}$ retrieval using this spectral region only.

In the ACE-FTS retrieval process, which uses a globalfit method in a general non-linear least squares minimization scheme (Boone et al., 2005), a set of microwindows that vary with altitude in the fundamental band and in the overtone band are used to retrieve CO. The use of the intense 1-0 band provides information on the upper parts of the atmosphere, whereas the 2-0 band provides information at the lowest alti-

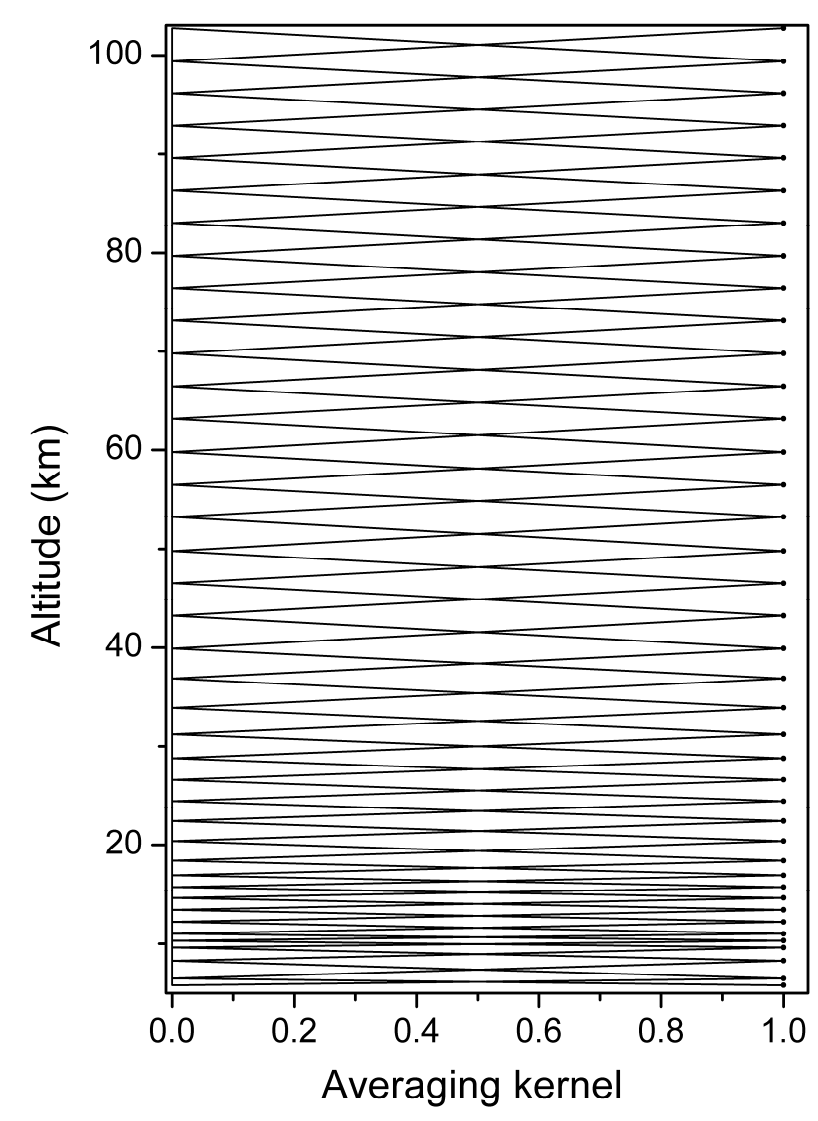

Fig. 3. Typical CO averaging kernels for ACE-FTS, using the microwindows shown in Fig. 2, and an Optimal Estimation Method without a priori constraints. The vertical resolution is $\sim 2 \mathrm{~km}$ in the troposphere and $4 \mathrm{~km}$ above, for a beta angle of $-50.6^{\circ}$. At low beta angles, the vertical resolution might reach $6 \mathrm{~km}$ at the highest altitudes.

tudes, when the signal from the fundamental band saturates. The microwindow sets used for the ACE-FTS version 2.2 retrievals are indicated in Fig. 2 and listed in Table 1. The molecules that are explicitly included as interferers in the retrieval of the target molecule are reported, and the mixing 
a) January-February-March

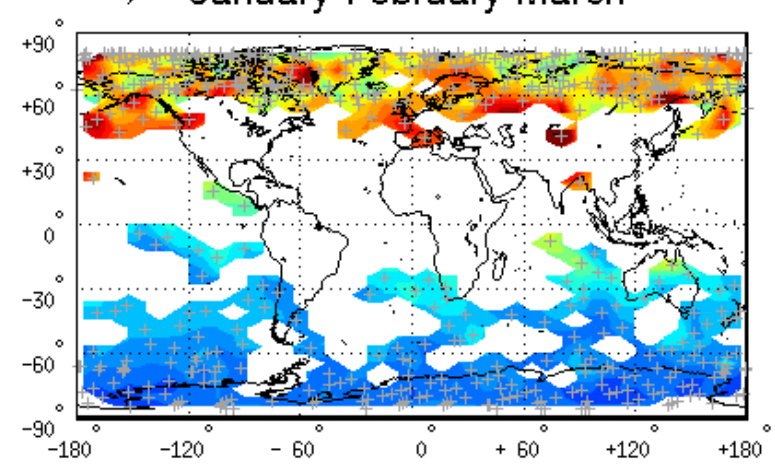

c) July-August-September

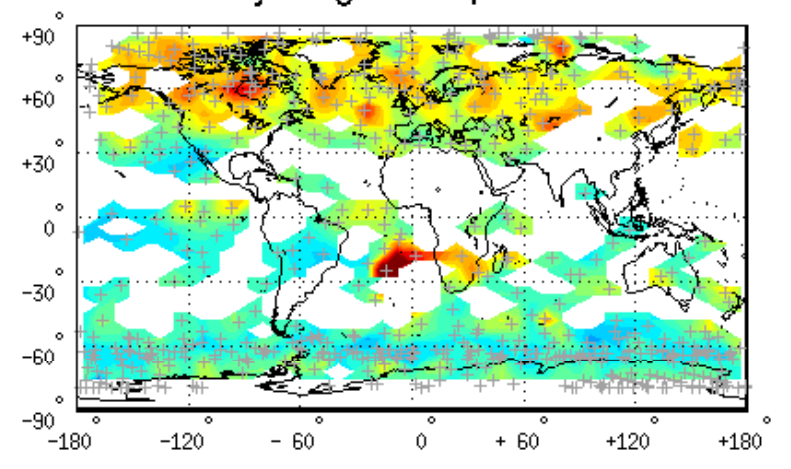

b) April-May-June

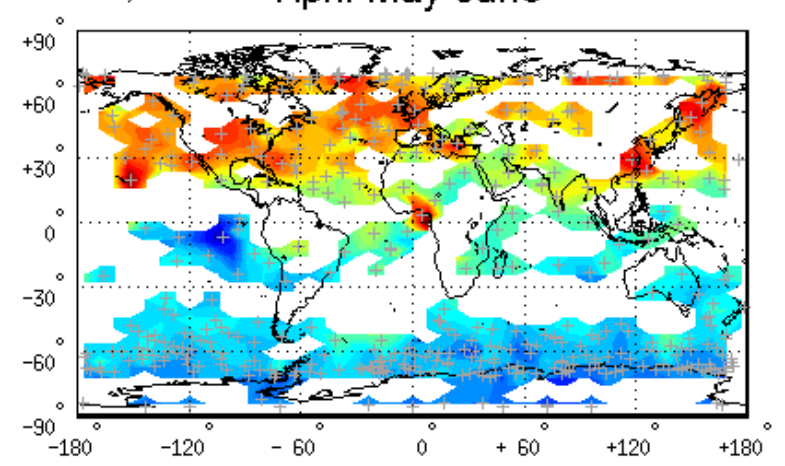

d) October-November-December

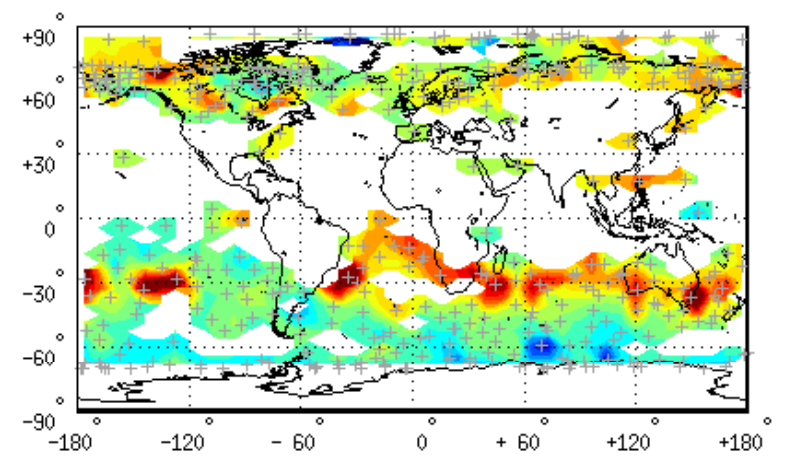

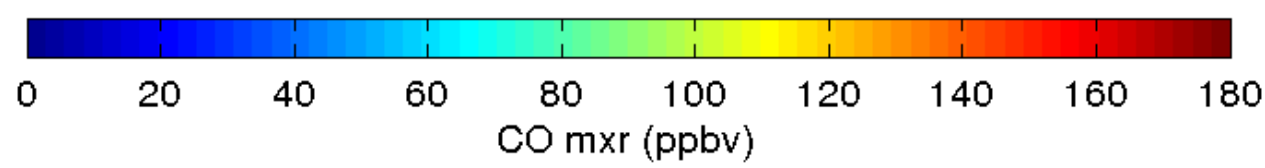

Fig. 4. ACE-FTS CO seasonal measurements in 2005 at $7.5 \mathrm{~km}$. The data are interpolated to a $4^{\circ}$ latitude $\times 8^{\circ}$ longitude grid. The grey crosses indicate the ACE-FTS measurement locations (tangent heights). The lowest altitude measured by the ACE-FTS varies with the satellite orbit and the presence of clouds.

ratio profiles for these interfering gases are fitted simultaneously with the target CO profile. The ACE-FTS profiles are provided on a $1-\mathrm{km}$ vertical grid. To obtain the $1-\mathrm{km}$ grid data products, an a posteriori piecewise quadratic interpolation scheme method is used to interpolate between the altitudes of the original measurement grid. It is worth noting that sometimes the first $\mathrm{CO}$ level (at low altitude) should be treated with caution. The v2.2 data products are provided with a fitting error calculated for each altitude. A detailed budget of the retrieval and instrumental errors can be estimated (see Clerbaux et al., 2005). It includes contributions from the instrumental noise, from the instrument line shape function, from the so-called smoothing effect (the fact that the information is integrated over several $\mathrm{km}$ on the vertical), and from uncertainties in the temperature and interfering trace gases profiles. Table 2 summarizes the retrieval errors in terms of partial columns, as currently estimated for the ACE-FTS version $2.2 \mathrm{CO}$ retrievals. The error is the largest (2\%) for the 6-12 km columns, where the errors due to interfering species and temperature uncertainties have the strongest impact; it decreases to $0.5 \%$ for the $12-25$ and $25-$ $50 \mathrm{~km}$ columns and finally increases again to about $1 \%$ for the 50-80 and $80-100 \mathrm{~km}$ columns. The errors in the individual retrieved levels of the CO profile is less than $10 \%$ in the troposphere (except for the very first levels below $8 \mathrm{~km}$ ) and the stratosphere, and between 5 and $20 \%$ at higher altitudes. The measurement noise provides the dominant contribution to the error budget over the entire altitude range, with contributions ranging from $60-70 \%$ in the upper troposphere and the stratosphere to more than $90 \%$ higher up (Table 2).

\subsection{ACE-FTS CO distributions}

The very high signal-to-noise ratio achieved by the ACE-FTS and its ability to sound deep down in the atmosphere provide profile measurements of weakly absorbing species into the upper troposphere. This excellent tropospheric sounding performance has been highlighted in several recent papers 
a) January-February-March

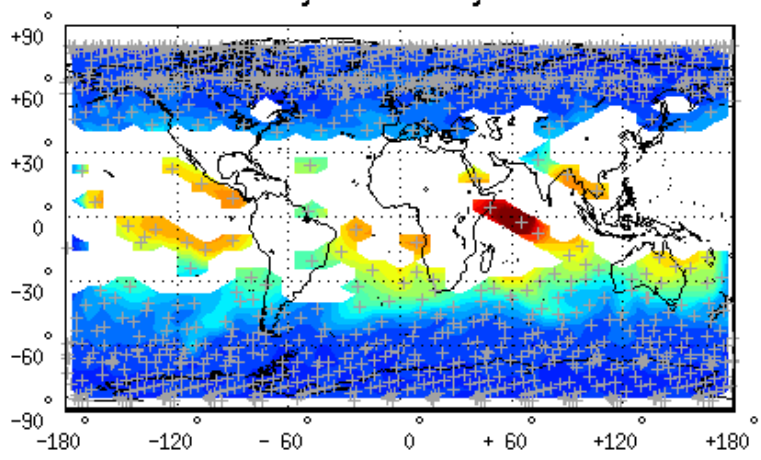

c) July-August-September

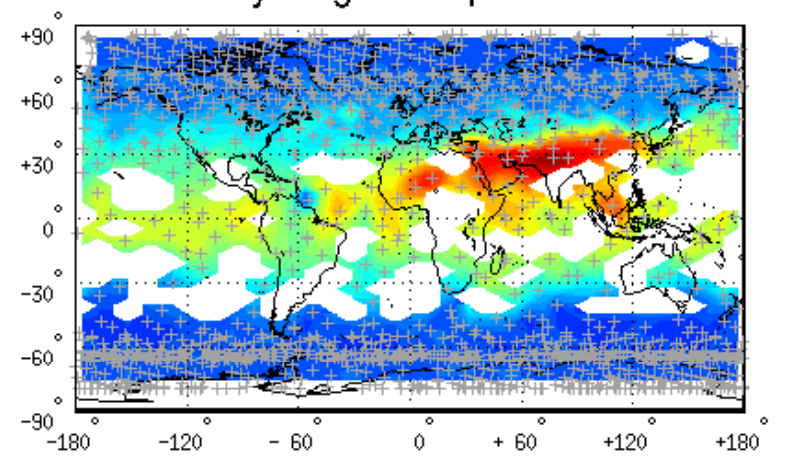

b) April-May-June

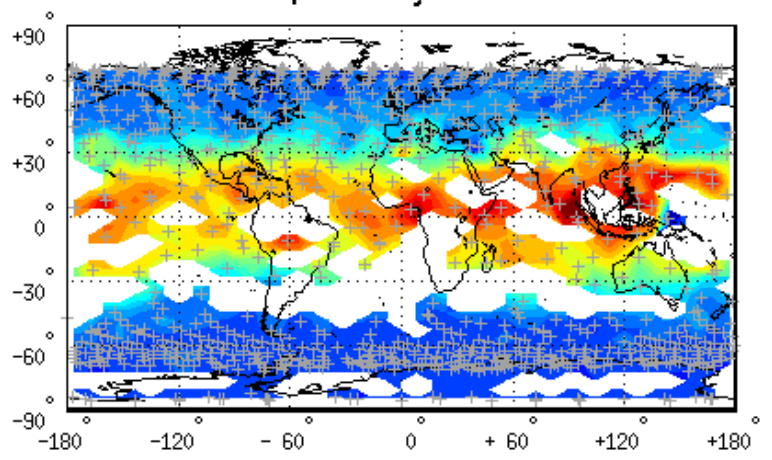

d) October-November-December

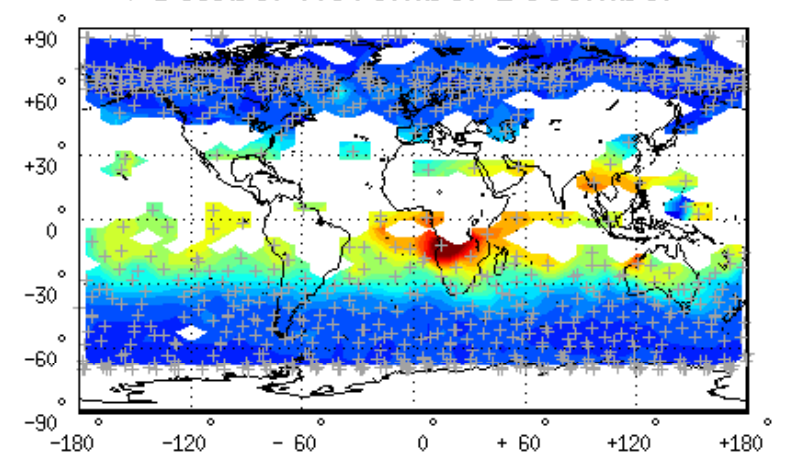

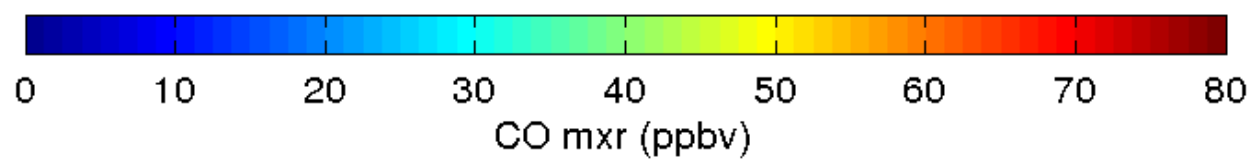

Fig. 5. ACE-FTS CO seasonal measurements in 2005 at $16.5 \mathrm{~km}$. The data are interpolated to a $4^{\circ}$ latitude $\times 8^{\circ}$ longitude grid. The grey crosses indicate the ACE-FTS measurement locations (tangent heights). Note that the tropical latitudes are not well covered in JanuaryFebruary-March and October-November-December as the satellite orbit was optimized to study the polar regions in winter.

(Rinsland et al., 2006b, 2007a, 2007b; Coheur et al., 2007; Dufour et al., 2007; Turquety et al., 2008). Previous scientific studies have discussed the CO vertical profiles (v1.0 and v2.2) obtained from ACE-FTS since March 2004 (just after scientific commissioning was completed on 21 February 2004) (e.g. Clerbaux et al., 2005 (v1.0); Rinsland et al., 2005; Folkins et al., 2006). For CO, version 2.2 provides improved performance in the troposphere, as many microwindows sensitive to lower altitudes were added to the retrievals.

The altitude spacing of the ACE-FTS measurements, controlled by the scan time and the orbit of the satellite, varies with the beta angle (the angle between the satellite velocity vector and a vector from the Earth to the Sun). The altitude spacing ranges from $2 \mathrm{~km}$ for long occultations with high beta (around $55^{\circ}$ ) to $6 \mathrm{~km}$ when the sun sets (or rises) exactly perpendicular to the Earth horizon (occultations with beta angle zero). Note that the altitude spacing compresses at low altitudes (below about $40 \mathrm{~km}$ ), primarily a consequence of refraction distorting the solar image viewed through the at- mosphere. This is clearly seen from Fig. 3, which shows the vertical sensitivity functions, known as averaging kernels, for a typical CO retrieval using an Optimal Estimation Method (Rodgers, 2000) without a priori constraints, such as to resemble the general least-square retrievals performed operationally for version 2.2. For the particular case of Fig. 3, the vertical sampling is as good as $1.5 \mathrm{~km}$ in the troposphere and around $4 \mathrm{~km}$ in the mesosphere. There have been improvements in the retrievals and averaging kernels near $20-25 \mathrm{~km}$, compared to v1.0 (Clerbaux et al., 2005), due to the combined use of the 1-0 and 2-0 ro-vibrational bands to retrieve $\mathrm{CO}$ at those altitudes.

After 3.5 years of operation, ACE-FTS observations have been performed all over the globe, however there were more frequent measurements at high latitudes, as the primary goal of the mission was to study the polar ozone chemistry. Figures 4 to 6 provide representative plots of $\mathrm{CO}$ at different altitude levels (mid-troposphere, upper troposphere/lower stratosphere (UTLS), and stratosphere/mesosphere) for the 
a)

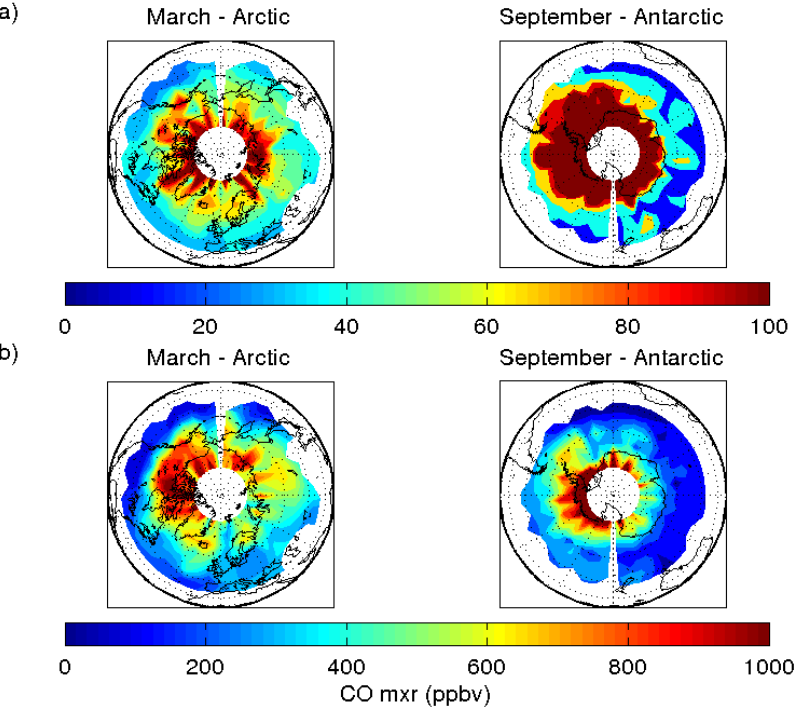

Fig. 6. ACE-FTS CO polar measurements in March and September 2005 at (a) $49.5 \mathrm{~km}$ and (b) at $59.5 \mathrm{~km}$. The data are interpolated to a $6^{\circ}$ latitude $\times 8^{\circ}$ longitude grid. We used polar projections over the Arctic (left plots) and the Antarctic (right plots) to illustrate the descent of CO-rich air masses in polar vortex situations.

year 2005. The years 2004 and 2006 (not shown here) exhibit similar high concentration values at specific locations/altitudes. Figure 4 illustrates the seasonal $\mathrm{CO}$ abundance distribution as measured by ACE-FTS in the midtroposphere (around $7.5 \mathrm{~km}$ ) for different seasons in 2005 . As can be expected (e.g. Clerbaux et al., 2004; Edwards et al., 2004), in the Northern Hemisphere, most of the pollution is associated with urban activity, with persistent high values above China (see Fig. 4b) and elevated levels over US, Europe and Asia in winter and spring (Fig. 4a and b). $\mathrm{CO}$ levels are lower in the Northern Hemisphere during summer and fall, when sunlight produces high $\mathrm{OH}$ levels which activate chemical loss of CO. In the Southern Hemisphere, the $\mathrm{CO}$ pollution plumes emitted locally, where vegetation burning occurs, such as in South America, Africa and Australia spread from regional to global scales. As reported by others (e.g. http://earthobservatory.nasa.gov/Newsroom/ NewImages/images.php3?img_id=17724) intense fire activity and hence high $\mathrm{CO}$ levels were observed (starting from September 2005) over the Amazon basin, with some additional contribution from fires in Southern Africa. The transported plume can be observed in Fig. $4 \mathrm{c}$ and d, around $30^{\circ} \mathrm{S}$.

In the UTLS, vertical transport may be investigated from the satellite CO vertical distributions (Notholt et al., 2003; Edwards et al., 2006; Ricaud et al., 2007; Park et al., 2008). Figure 5 a-d shows the global scale seasonal distributions at $16.5 \mathrm{~km}$ altitude, from which the high $\mathrm{CO}$ concentrations from convection occurring at tropical latitudes can clearly be seen. The plots illustrate the seasonal changes in convective outflow and biomass burning activity. From July to September (Fig. 5c), when the Asian summer monsoon is the dominant circulation feature, high levels of $\mathrm{CO}$ are observed over Asia (also see Park et al., 2008). During the other months (Fig. 5b, d), maximum amounts are observed over Africa, South America and Asia, but horizontal transport can be observed throughout the tropics.

Figure 6a-b illustrates the strong downward transport of $\mathrm{CO}$-rich air in the winter polar vortex. The $\mathrm{CO}$ produced in the lower thermosphere from $\mathrm{CO}_{2}$ photolysis is transported to the middle stratosphere by the mean meridional circulation (Kasai et al., 2005b; Velasco et al., 2007). The plots show the descent of CO-rich air produced around $80 \mathrm{~km}$ when vortex situations occur, in March over the Arctic pole (Fig. 6, left plots) and in September over the Antarctic (Fig. 6, right plots). A complete discussion of the effects of unusual meteorological conditions on transport and chemistry for the 2004-2006 period is described in Manney et al. (2008, this Special issue).

\section{Correlative $\mathrm{CO}$ measurements}

\subsection{The ACE validation exercise}

The validation of the ACE-FTS version 2.2 data is organized by data product (see the other papers of this Special issue). $\mathrm{CO}$ data from the first three years of the mission, extending from February 2004 (since the first ACE-FTS CO data became available) to the end of 2006, were made available to the validation team and are included in this paper. Primarily, the 1-km interpolated grid data were used in the comparisons.

Validation data used for these $\mathrm{CO}$ comparisons were provided by eleven ground-based stations, from routine airborne measurements, from one accurate high-altitude balloonborne observation, and from five satellite instruments (two using nadir observations, three using limb-viewing observations). Each instrument uses a different measurement technique, sounding geometry, and dedicated retrieval algorithm (which relies on a forward radiative transfer code, a spectroscopic database, and a minimization scheme) to extract the desired $\mathrm{CO}$ abundances from the raw data (see Table 3). All the instruments reported here used the HITRAN spectroscopic database (Rothman et al., 2005). Although the HITRAN edition might differ, the changes did not concern the CO line parameters and it was verified (E. Mahieu, personal communication) that it did not impact the retrieved results.

The $\mathrm{CO}$ measurements are retrieved over different altitude ranges (see Fig. 1 for a representation of the altitude spanned for each device), with different vertical resolutions and maximum sensitivity. To properly account for the different vertical sensitivities of the correlative observations, the $\mathrm{CO}$ profile of the instrument with the higher profiling capability is smoothed by convolution with the averaging kernel functions 
Table 3. Ground-based, airborne and satellite instruments used for the ACE-FTS CO validation.

\begin{tabular}{|c|c|c|c|c|c|c|}
\hline Instrument & Location & $\begin{array}{l}\text { Vertical sensitivity } b / \\
\text { resolution }\end{array}$ & Estimated accuracy & Time period & Coincidence criteria & $\begin{array}{l}\text { Number of } \\
\text { coincidences }\end{array}$ \\
\hline \multicolumn{7}{|c|}{ FTIR Ground-based measurements } \\
\hline THULE & $76.5^{\circ} \mathrm{N}, 68^{\circ} \mathrm{W}$ & $0.2-25 \mathrm{~km}$ & $<10 \%$ & $2004 / 03-2006 / 03$ & $24 \mathrm{~h} / 1000 \mathrm{~km}$ & 20 \\
\hline KIRUNA $^{a}$ & $67.8^{\circ} \mathrm{N}, 20.4^{\circ} \mathrm{E}$ & $0-25 \mathrm{~km}$ & $\begin{array}{l}0-10 \mathrm{~km}: 2 \% \\
>10 \mathrm{~km}: 15-20 \%\end{array}$ & $2004 / 03-2006 / 03$ & $24 \mathrm{~h} / 1000 \mathrm{~km}$ & 39 \\
\hline POKER FLAT & $65.1^{\circ} \mathrm{N}, 147.4^{\circ} \mathrm{W}$ & $0-24 \mathrm{~km}$ & $\begin{array}{l}\text { Tot_col: } 3.5 \% \\
\text { Part_col: } 10-15 \%\end{array}$ & $2004 / 03$ & $24 \mathrm{~h} / 1000 \mathrm{~km}$ & 5 \\
\hline HARESTUA & $60.2^{\circ} \mathrm{N}, 10.8^{\circ} \mathrm{E}$ & $0.5-25 \mathrm{~km}$ & $\begin{array}{l}0-10 \mathrm{~km}: 3.5 \% \\
>10 \mathrm{~km}: 15-25 \%\end{array}$ & 2004/09-2005/07 & $24 \mathrm{~h} / 1000 \mathrm{~km}$ & 12 \\
\hline ZUGSPITZE & $47.4^{\circ} \mathrm{N}, 11^{\circ} \mathrm{E}$ & $\begin{array}{l}3-25 \mathrm{~km} \\
4 \mathrm{~km} \text { tropo } \\
10 \mathrm{~km} \text { strato }\end{array}$ & $5-10 \%$ & 2004/06-2006/07 & $24 \mathrm{~h} / 1000 \mathrm{~km}$ & 21 \\
\hline JUNGFRAUJOCH & $46.55^{\circ} \mathrm{N}, 7.98^{\circ} \mathrm{E}$ & $3.58-25 \mathrm{~km}$ & $<10 \%$ & $2004 / 07-2006 / 07$ & $24 \mathrm{~h} / 1000 \mathrm{~km}$ & 21 \\
\hline TORONTO & $43.66^{\circ} \mathrm{N}, 79.4^{\circ} \mathrm{W}$ & $0-25 \mathrm{~km}$ & $\begin{array}{l}\text { Tot_col: } 2.6 \% \\
\text { Tropo_col: } 2.7 \% \\
\text { Strato_col: } 7.4 \%\end{array}$ & 2004/06-2006/06 & $24 \mathrm{~h} / 1000 \mathrm{~km}$ & 8 \\
\hline IZANA $^{a}$ & $28.3^{\circ} \mathrm{N}, 16.5^{\circ} \mathrm{W}$ & $0-25 \mathrm{~km}$ & $\begin{array}{l}0-10 \mathrm{~km}: 2 \% \\
>10 \mathrm{~km}: 15-20 \%\end{array}$ & $2004 / 08-2005 / 08$ & $24 \mathrm{~h} / 1000 \mathrm{~km}$ & 4 \\
\hline LA REUNION & $21.5^{\circ} \mathrm{S}, 55.5^{\circ} \mathrm{E}$ & $0-20 \mathrm{~km}$ & $7-20 \mathrm{~km}: 12-17 \%$ & $2004 / 08-2004 / 10$ & $24 \mathrm{~h} / 15^{\circ}$ lon, $10^{\circ}$ lat & 3 \\
\hline WOLLONGONG & $34.5^{\circ} \mathrm{S}, 151^{\circ} \mathrm{E}$ & $0-25 \mathrm{~km}$ & $\begin{array}{l}\text { Tot_col: } 3 \% \\
0-12 \mathrm{~km}: \\
4 \%>12 \mathrm{~km}: 10 \%\end{array}$ & $2004 / 10-2005 / 11$ & $24 \mathrm{~h} / 1000 \mathrm{~km}$ & 5 \\
\hline \multicolumn{7}{|c|}{ MW Ground-based measurements } \\
\hline CERVINIA & $48.9^{\circ} \mathrm{N}, 7.7^{\circ} \mathrm{E}^{c}$ & $35-90 \mathrm{~km}$ & Column density: $10.5 \%$ & $2004 / 12$ & $24 \mathrm{~h} / 1000 \mathrm{~km}$ & 2 \\
\hline \multicolumn{7}{|c|}{ Airborne measurements } \\
\hline SPIRALE & $67.7^{\circ} \mathrm{N}, 21.5^{\circ} \mathrm{E}$ & $13-27 \mathrm{~km}$ & $6 \%$ & $2006 / 01$ & $24 \mathrm{~h} / 1000 \mathrm{~km}$ & 1 \\
\hline MOZAIC & $20^{\circ} \mathrm{N}-51^{\circ} \mathrm{N}, 119^{\circ} \mathrm{W}-140^{\circ} \mathrm{E}$ & $5-12 \mathrm{~km}$ & $\pm 5 \mathrm{ppbv}+5 \%$ & $2004 / 04-2005 / 10$ & $24 \mathrm{~h} / 9^{\circ}$ lat, $10^{\circ}$ lon & 108 \\
\hline \multicolumn{7}{|c|}{ Satellite measurements } \\
\hline MOPITT/Terra (nadir) & all latitudes, all longitudes & $0-16 \mathrm{~km}$ & $10 \%$ & $2004 / 02-2006 / 12$ & same day $/ 5^{\circ}$ lat, $5^{\circ}$ lon & 3485 \\
\hline TES/Aura (nadir) & all latitudes, all longitudes & $0-16 \mathrm{~km}$ & $10 \%$ & 2004/09-2006/11 & $24 \mathrm{~h} / 300 \mathrm{~km}$ & 3855 \\
\hline MIPAS/Envisat (limb) & $51^{\circ} \mathrm{N}-81^{\circ} \mathrm{N}, 97^{\circ} \mathrm{W}-180^{\circ} \mathrm{E}$ & $\begin{array}{l}10-70 \mathrm{~km} \\
6-12 \mathrm{~km}\end{array}$ & $\begin{array}{l}\text { Tropo: } 10-30 \% \\
\text { Strato: } 30-70 \% \\
45-70 \mathrm{~km}: 10-30 \%\end{array}$ & $2004 / 02-2004 / 03$ & $18 \mathrm{~h} / 800 \mathrm{~km}$ & 99 \\
\hline SMR/Odin (limb) & all latitudes, $0^{\circ}-186^{\circ} \mathrm{E}$ & $\begin{array}{l}20-110 \mathrm{~km} \\
<65 \mathrm{~km}: 2-4 \mathrm{~km} \\
>65 \mathrm{~km}: \sim 6 \mathrm{~km}\end{array}$ & $\begin{array}{l}\text { Strato: } 25 \text { ppbv } \\
\text { Meso:1-2 ppmv }\end{array}$ & $2004 / 03-2006 / 02$ & $10 \mathrm{~h} / 9^{\circ}$ lat, $10^{\circ} \mathrm{lon}$ & 99 \\
\hline \multirow[t]{2}{*}{ MLS/Aura (limb) } & $82^{\circ} \mathrm{N}-82^{\circ} \mathrm{S}$, all longitudes & $\begin{array}{l}10-85 \mathrm{~km} \\
3-4 \mathrm{~km}\end{array}$ & Strato: $30 \%$ & $2004 / 09-2006 / 10$ & same day $/ 0.75^{\circ}$ lat, $12^{\circ}$ lon & 2156 \\
\hline & & & Meso: $20 \%$ & & & \\
\hline
\end{tabular}

${ }^{a}$ These stations use PROFFIT 9.2. version 9 inversion algorithm (Hase et al., 2004), and the retrievals are performed on a log vmr-scale. All other GB-FTIR stations use SFIT2 inversion algorithm (different versions) (Pougatchev and Rinsland, 1995; Rinsland et al., 1998). Note that both codes were compared in an extensive study, resulting in an agreement of columns of better than 1\% (Hase et al., 2004).

${ }^{b}$ FTIR stations might have some sensitivity higher in the atmosphere, as demonstrated in Velazco et al., (2007).

${ }^{c}$ Location for Cervinia measurement is at intersection of slant-angle radiometer beam with $60 \mathrm{~km}$ altitude, not station location.

of the instrument with the lowest vertical sensitivity (Rodgers and Connors, 2003):

$\mathbf{x}_{\text {smoothed }}=\mathbf{x}_{a, \text { low }}+\mathbf{A}_{\text {low }}\left(\mathbf{x}_{\text {high }}-\mathbf{x}_{a, \text { low }}\right)$

where $\mathbf{x}_{\text {high }}$ is the high resolution profile, $\mathbf{x}_{a, \text { low }}$ is the a priori profile used for the retrieval of the low resolution profile, and $\mathbf{A}_{\text {low }}$ is the averaging kernel matrix, with $\mathbf{A}=\partial \hat{\mathbf{x}} / \partial \hat{\mathbf{x}}$, characterizing the low resolution profiles. The rows of $\mathbf{A}$ define the vertical resolution of the retrieval (full width at half maximum), and the trace of the matrix defines the number of statistically independent elements that can be retrieved, or degrees of freedom for signal (DOFS).

\subsection{Ground-based data}

Eleven ground-based stations routinely measuring $\mathrm{CO}$ profiles/columns at different locations around the globe contributed to this validation exercise. Ten of these stations use FTIR spectrometers to sound the troposphere and lower stratosphere, and one is operating in the millimeter wave spectral range.

\subsubsection{FTIR measurements}

FTIR spectrometers make direct solar absorption observations throughout the day, under clear sky conditions. The infrared spectral range that is covered extends from about 600 to $4300 \mathrm{~cm}^{-1}$, a range similar to that of ACE-FTS. In this spectral range, a very large number of species of atmospheric relevance can be detected. Profiles or partial column 


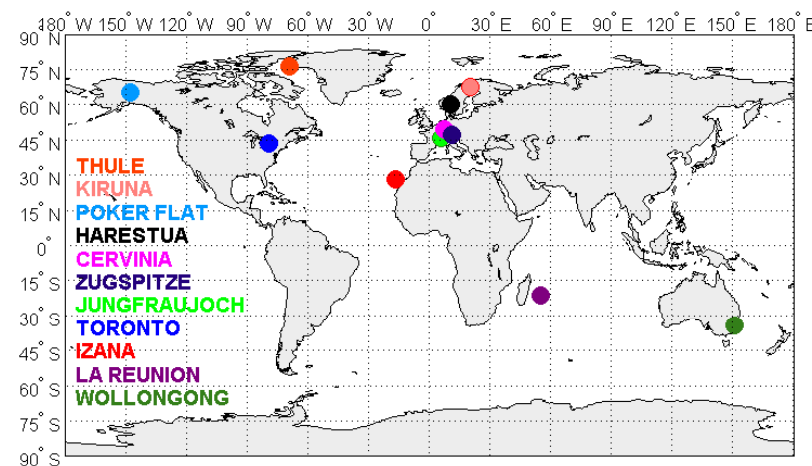

Fig. 7. Geographic locations of the 11 ground-based validation stations used in this paper. Note that there are only two stations located in the Southern Hemisphere (La Réunion and Wollongong), and that four stations are located at latitudes where dynamics can be perturbed by the location of the polar vortex (Thule, Kiruna, Poker Flat, and Harestua).

CO data can be derived (Notholt et al., 2003; Barret et al., 2003; Hase et al., 2004). The FTIR measurements contains about two pieces of information that allow to retrieve $\mathrm{CO}$ abundances in the lower to middle troposphere and in the upper troposphere-lower stratosphere, almost independently.

Figure 7 and Table 3 provide the geographical distributions along with retrieval information for the ground-based ACE-FTS CO validation stations, with the following abbreviations:

- THULE (Greenland, Goldman et al., 1999),

- KIRUNA (Sweden, Blumenstock et al., 2006),

- POKER FLAT (Alaska, Kasai et al., 2005a),

- HARESTUA (Norway, Paton-Walsh et al., 1997),

- ZUGSPITZE (Germanic Alps, Sussmann and Borsdorff, 2007),

- JUNGFRAUJOCH (Swiss Alps, Rinsland et al., 2000),

- TORONTO (Canada, Wiacek et al., 2007),

- IZANA (Canary Islands, Schneider al., 2005),

- LA REUNION (Indian Ocean, Senten et al., 2008),

- WOLLONGONG (Australia, Jones et al., 2007).

\subsubsection{Microwave measurements}

Microwave spectrometers observe molecular rotational/vibrational spectra in emission from thermally excited states in the spectral range $\sim 20-300 \mathrm{GHz}$. They can therefore operate day or night, limited only by tropospheric opacity due primarily to varying water vapour column density. They are not affected by aerosol loading. Since

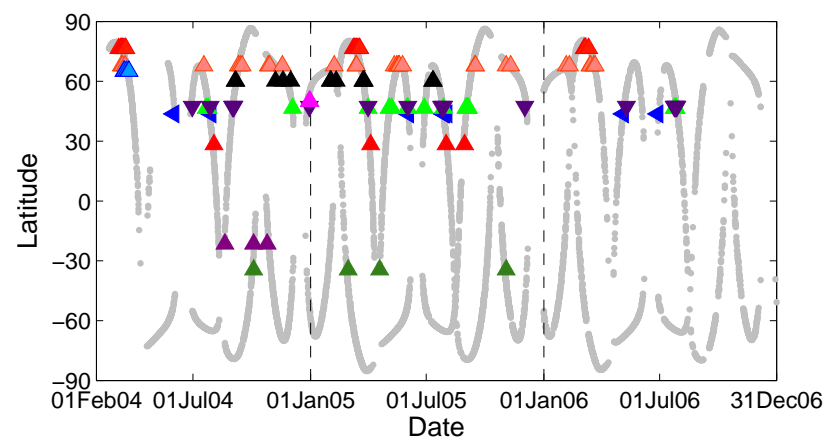

Fig. 8. Coincidences between ACE-FTS measurements (in light gray, ACE occultation latitude versus time of year) and the ground based stations, for the three years of the mission. The color code for each station is the same as in Fig. 7. The coincidence criteria are provided in Table 3 . Note that if time coincidences occur for a same station, symbols might be superposed.

they observe in emission, they are not self-calibrating, and must be independently calibrated against millimeter sources of known intensity. For the instrument at CERVINIA (de Zafra et al., 2004), when used in a radiometer mode to get total column density, this calibration uncertainty, along with uncertainty in continuous measurements of tropospheric attenuation, are the only significant sources of error. For this instrument, observations are made at a slant angle of 9-10 degrees in a due north direction, giving a stratospheric/mesospheric point of intersection about 3 degrees north of the ground station location, and this has been used in considering closest matches with ACE-FTS measurements. The location of this station, in the Italian alps, and the retrieval details are also reported in Fig. 7 and Table 3.

\subsection{Airborne data}

\subsubsection{SPIRALE (high altitude balloon)}

The SPectroscopie Infra-Rouge d'Absorption par Lasers Embarqués (SPIRALE) is a balloon-borne six tunable diode laser absorption spectrometer (Moreau et al., 2005). It is routinely operated at all latitudes, in particular as part of European satellite validation campaigns (Odin and Envisat). It can perform simultaneous in situ measurements of about ten long-lived and short-lived chemical species from about 10 to $35 \mathrm{~km}$ height, with high sampling frequency $(\sim 1 \mathrm{~Hz})$, thus enabling a vertical resolution of a few meters depending on the ascent rate of the balloon. The diode lasers emit in the mid-infrared (from 3 to $8 \mu \mathrm{m}$ ) and the beams are injected into a multipass Herriott cell that is located under the gondola and is largely exposed to ambient air. The cell $(3.5 \mathrm{~m}$ long) is deployed during the ascent when pressure is lower than $300 \mathrm{hPa}$. The multiple reflections obtained between the 

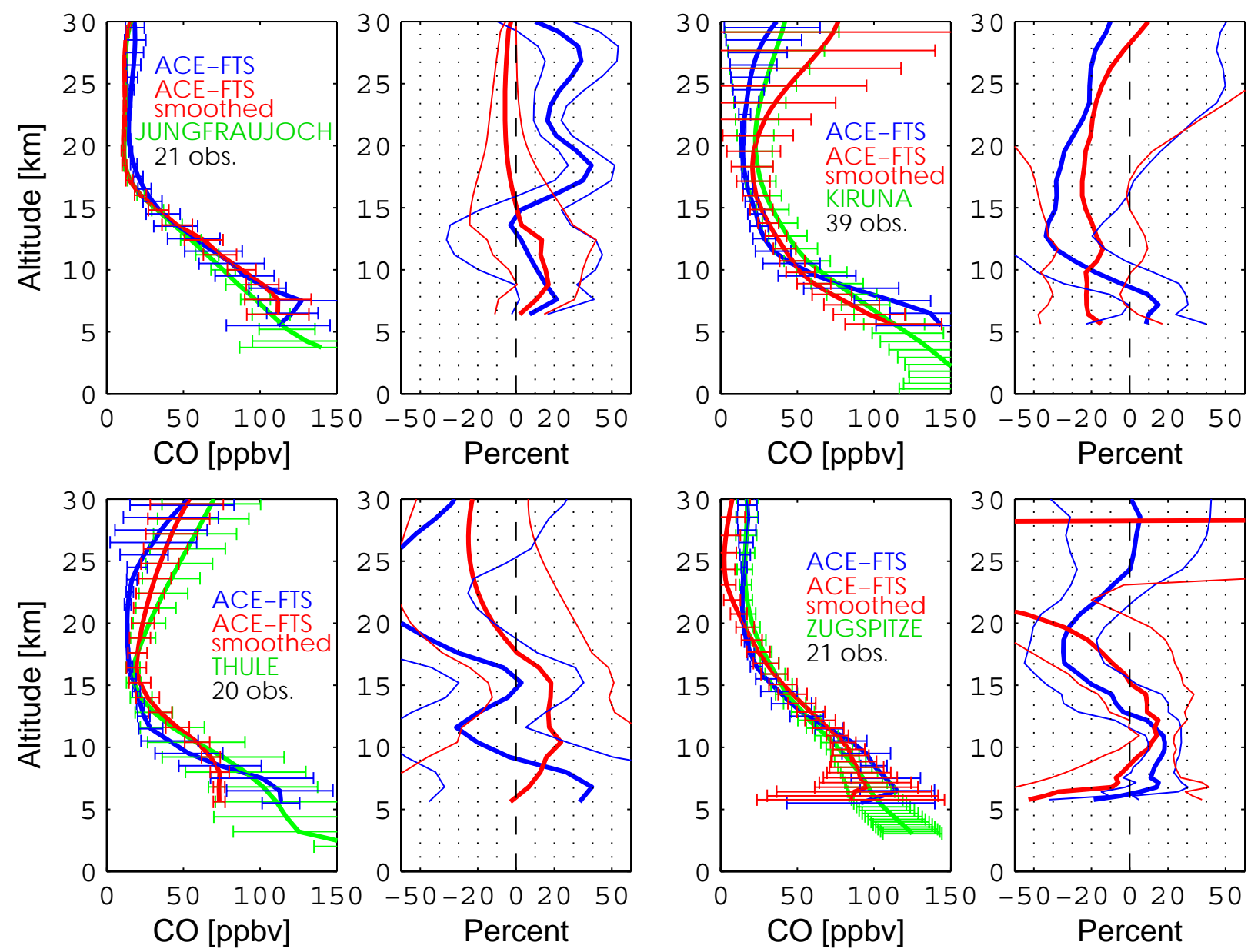

Fig. 9. Left panel, for each ground-based (GB) station (Jungfraujoch, Kiruna, Thule and Zugspitze): Averaged CO mixing ratio profiles and variability for ACE-FTS (in blue: raw data, in red: after treatment with the corresponding ground-based averaging kernels) and for the collocated corresponding ground-based measurements (green). Right panel, for each ground-based station : averaged percent difference between ACE-FTS and $\mathrm{GB}\left(\mathrm{CO}_{\mathrm{ACE}}-\mathrm{CO}_{\mathrm{GB}} / 1 / 2\left(\mathrm{CO}_{\mathrm{ACE}}+\mathrm{CO}_{\mathrm{GB}}\right)\right)$ calculated for all the coincident observations (thick line), along with their standard deviation (thin lines).

two cell mirrors give a total optical path of $430.78 \mathrm{~m}$. Species concentrations are retrieved from direct infrared absorption, by fitting the experimental spectra to spectra calculated using the HITRAN 2004 database (Rothman et al., 2005). Specifically, the ro-vibrational line at $2086.3219 \mathrm{~cm}^{-1}$ was used for CO.

\subsubsection{MOZAIC (airplane)}

The MOZAIC program (Marenco et al., 1998) has equipped five commercial airliners with instruments to measure ozone and relative humidity since 1994, and carbon monoxide since 2001. Measurements are taken from take-off to landing (Thouret et al., 1998). Based on an infrared analyser, the carbon monoxide measurement accuracy is estimated at $\pm(5 \mathrm{ppbv}+5 \%)$ for a $30 \mathrm{~s}$ response time (Nedelec et al.,
2003). The five MOZAIC aircraft make near-daily flights between Europe and a variety of destinations throughout the world. Measurements for more than 26000 long-haul flights are recorded in the MOZAIC data base that is freely accessible for scientific use (URL: http://mozaic.aero.obs-mip.fr/ web/).

\subsection{Nadir-looking satellites}

\subsubsection{MOPITT/Terra}

The Measurements Of Pollution In The Troposphere (MOPITT) remote sensing instrument was developed by Canada and the US and was launched aboard the EOS Terra satellite in December 1999. It began routine measurements in March 2000 and is still in operation. The Terra spacecraft is in a near-circular, sun-synchronous orbit with an inclination of 
Table 4. Averaged percent difference and standard deviation between ACE-FTS and each ground-based (GB) station. The calculation was done for partial $\mathrm{CO}$ columns, for each coincident set of profiles using $\left(100 \times\left|\left(\mathrm{CO}_{\mathrm{ACE}}-\mathrm{CO}_{\mathrm{GB}}\right)\right|\right) / 1 / 2\left(\mathrm{CO}_{\mathrm{ACE}}+\mathrm{CO}_{\mathrm{GB}}\right)$. Values in italics correspond to the calculation after smoothing with the GB averaging kernel functions. Values in parentheses correspond to calculation after filtering situations for which different air masses might have been sounded.

\begin{tabular}{lll}
\hline Ground-based station & Averaged relative difference $(\%)$ & Standard deviation $(\%)$ \\
\hline THULE & $37.1(30.8)$ & $29.7(21.5)$ \\
& $26.5(21.4)$ & $28.3(15.4)$ \\
KIRUNA & $31.3(31.2)$ & $24.2(23.8)$ \\
& $28.9(28.3)$ & $16.5(16.4)$ \\
POKER FLAT & 20.0 & 14.6 \\
& 15.6 & 8.5 \\
HARESTUA & $40.4(39.6)$ & $29.5(32.3)$ \\
& $19.0(19.9)$ & $16.7(18.3)$ \\
CERVINIA & 25.8 & 31.5 \\
ZUGSPITZE & 22.5 & 21.7 \\
& 24.3 & 21.6 \\
JUNGFRAUJOCH & 16.7 & 10.5 \\
& 16.3 & 10.9 \\
TORONTO & 24.5 & 11.2 \\
& 33.7 & 23.0 \\
IZANA & 13.2 & 8.9 \\
& 13.1 & 6.9 \\
LA REUNION & 18.5 & 15.3 \\
\multirow{2}{*}{ WOLLONGONG } & 13.3 & 6.9 \\
& 23.8 & 14.8 \\
\hline
\end{tabular}

approximately 98.2 degrees. The descending node crossing time is 10:30 a.m. MOPITT views the Earth over all latitudes with a pixel size of $22 \mathrm{~km}$ by $22 \mathrm{~km}$ and a cross-track swath that provides a near-global measurement of the distribution of $\mathrm{CO}$ every three days.

MOPITT operates by sensing infrared radiation from either the thermal emission/absorption at $4.7 \mu \mathrm{m}$ to measure $\mathrm{CO}$ profiles. The measurement technique exploits gas correlation radiometry to determine tropospheric concentrations. Operational MOPITT CO products available are currently based exclusively on thermal-channel radiances (Deeter et al., 2003; Emmons et al., 2004). The information content in MOPITT retrievals is better than a column in tropical and mid-latitude scenes, with some amount of profile shape information (DOFS between 1 and 1.8), and a maximum sensitivity around 5-8 km (Deeter et al., 2004). As the other thermal infrared instruments, MOPITT generally lacks sensitivity near the surface except during daytime and at locations where the thermal contrast (temperature gradient) between the surface and lower atmosphere is significant (Clerbaux et al., 2008).

This paper uses the version 3 retrievals from NASA Langley.

\subsubsection{TES/Aura}

The Tropospheric Emission Spectrometer (TES) is an infrared FTS on board the EOS Aura satellite launched in July 2004 (Beer, 2006). TES routinely operates in a nadir global survey mode with one-day-on followed by one-day-off cycles. The nadir footprint for a TES profile is $5 \mathrm{~km} \times 8 \mathrm{~km}$, separated by $180 \mathrm{~km}$ along orbit, since May 2005 . TES nadir spectra are recorded at $0.06 \mathrm{~cm}^{-1}$ resolution and small micro-windows in the $\mathrm{CO}(1-0)$ band are used for $\mathrm{CO}$ profile retrievals. The signal levels in the TES filter detecting $\mathrm{CO}$ spectral absorptions are greatly enhanced due to the improved optical alignment after an optical bench warm-up performed in December 2005. As a result, the DOFS and the precision in TES CO retrievals are improved (Rinsland et al., 2006a). The DOFS for TES CO are up to two in the tropics and become less than one at high latitudes.

TES data are distributed by the NASA Langley Atmospheric Science Data Center. The data version used in this paper is V002. TES data consists of profiles of CO reported at 24 levels per pressure decade (e.g., $1000 \mathrm{hPa}$ to $100 \mathrm{hPa}$ ) between the surface and $100 \mathrm{hPa}(\sim 16 \mathrm{~km})$. Together with the retrieved profiles, the averaging kernels, the a priori profiles, and the retrieval errors are provided in the data files. 


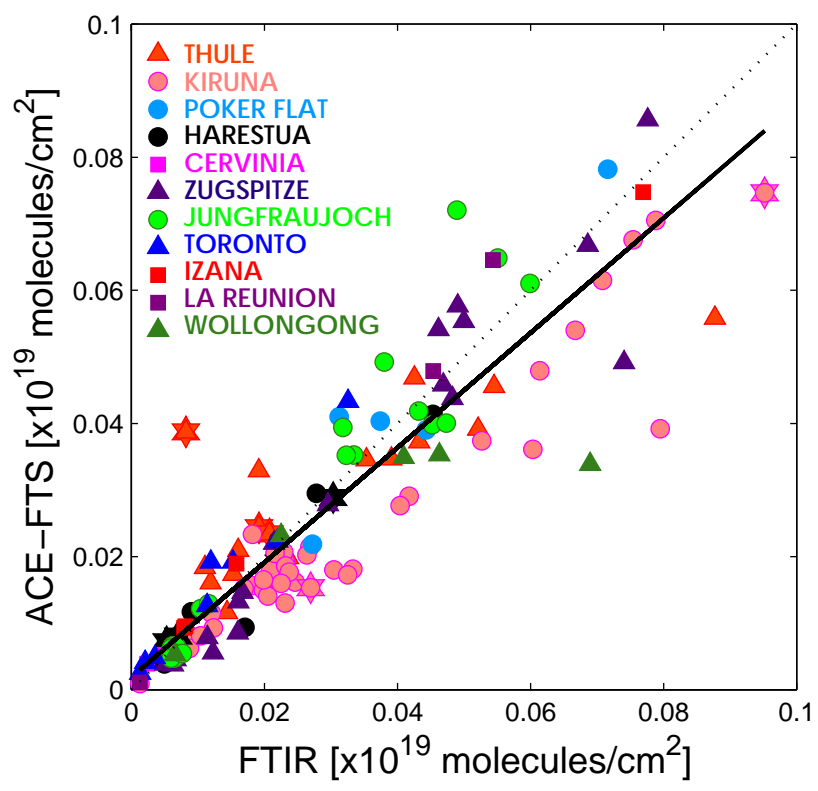

Fig. 10. Scatterplot of the ground-based CO partial column observations and the corresponding ACE-FTS CO partial columns calculated after treatment of profiles with the GB averaging kernel functions (except for the Cervinia station). The ground-based stations are identified by different colors (see legend). Each partial column is obtained by integration of the $\mathrm{CO}$ concentration from the lowest available ACE-FTS level (typically $6.5-8.5 \mathrm{~km}$ ) to the altitude indicated in Table 3. Density profiles were obtained by interpolating of ECMWF temperature and pressure fields to match the time and location of each measurement. Special symbols (star) are used when the calculated values are believed to correspond to significantly different airmasses, in polar vortex situations (see text). The correlation coefficient is 0.91 (slope 0.86 , intercept 0.0019 ).

\subsection{Limb-viewing satellites}

\subsubsection{MIPAS/Envisat}

The Michelson Interferometer for Passive Atmospheric Sounding (MIPAS) is a limb emission FTS operating in the mid infrared spectral region (Fischer et al., 2008). It is part of the Environmental Satellite (Envisat) which was launched into its sun-synchronous polar orbit, with $98.55^{\circ}$ inclination at about $800 \mathrm{~km}$ altitude, in March 2002. MIPAS operated from July 2002 to March 2004 at full spectral resolution $\left(0.035 \mathrm{~cm}^{-1}\right)$. Within this standard observation (nominal) mode, MIPAS covered the altitude range from 6 to $68 \mathrm{~km}$ with tangent altitudes from 6 to $42 \mathrm{~km}$ every $3 \mathrm{~km}$, and further tangent altitudes at $47,52,60$, and $68 \mathrm{~km}$. MIPAS passes the equator in southerly direction at 10:00 a.m. solar local time 14.3 times a day. During each orbit up to $72 \mathrm{limb}$ scans are recorded.

Vertical profiles of $\mathrm{CO}$ are among the 20 trace species retrieved with the dedicated scientific IMK-IAA MIPAS data processor (von Clarmann et al., 2003). CO 1-0 emissions at
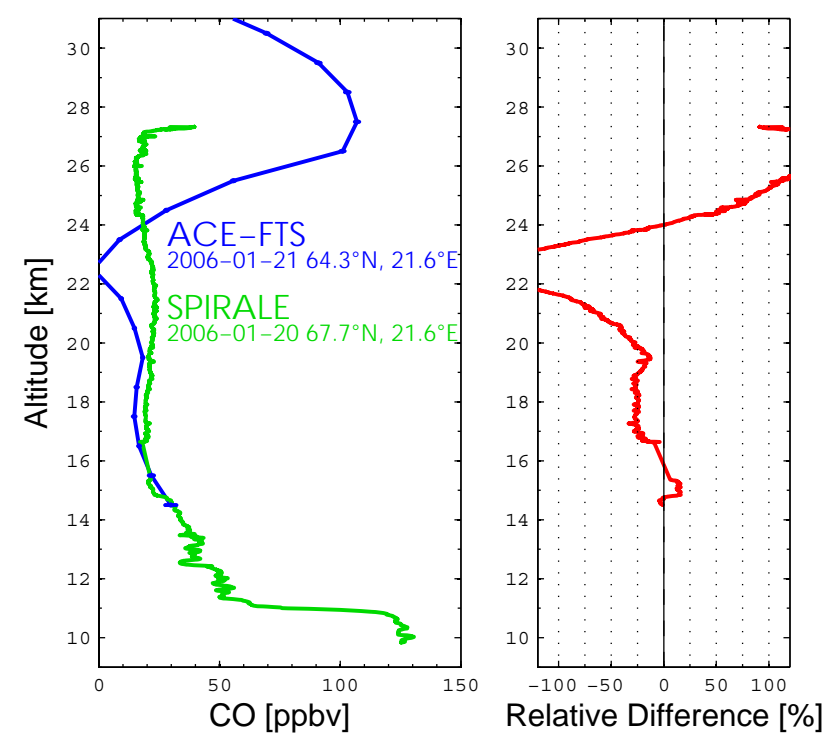

Fig. 11. Left: Averaged $\mathrm{CO}$ mixing ratio profile for ACE-FTS (blue) and for the co-located SPIRALE measurements (green). Right: The red line is the $\mathrm{CO}_{\mathrm{ACE}^{-}}$ $\mathrm{CO}_{\text {SPIRALE }} / 1 / 2\left(\mathrm{CO}_{\mathrm{ACE}}+\mathrm{CO}_{\text {SPIRALE }}\right)$ percentage difference.

$4.7 \mu \mathrm{m}$, strongly affected by non-local thermodynamic equilibrium (non-LTE) effects, are used in the retrieval scheme which fully accounts for non-LTE (Funke et al., 2007). In this study, we used MIPAS CO data (version 9.0) retrieved from MIPAS standard observations taken at full spectral resolution (spectra versions 4.61 and 4.62) during FebruaryMarch 2004. The MIPAS vertical resolution varies between 6 and $12 \mathrm{~km}$.

\subsubsection{SMR/Odin}

The Odin satellite was launched in February 2001 into a circular, sun-synchronous, quasi-polar orbit at $600 \mathrm{~km}$ altitude, with an inclination of $97.8^{\circ}$ and ascending node crossing at 18:00 local time (Murtagh et al., 2002). The Sub-Millimetre Radiometer (SMR) aboard Odin measures thermal emission lines at the Earth's limb in the $486-581 \mathrm{GHz}$ spectral range (Frisk et al., 2003). Measurements of $\mathrm{CO}$ and $\mathrm{O}_{3}$ in the SMR strato-mesospheric mode (vertical scan range of 7-110 km) are performed regularly (one or two days per month since 2004) by observing rotational lines at $576.27 \mathrm{GHz}$ (CO) and $576.52 \mathrm{GHz}\left(\mathrm{O}_{3}\right)$. The horizontal resolution is on the order of $600 \mathrm{~km}$, with a horizontal spacing along the orbit track of $\sim 950 \mathrm{~km}$.

The SMR CO data product discussed here is version225 (or CTSO-v225, for Chaîne de Traitement Scientifique Odin), the reference version maintained at the Laboratoire d'Aérologie (Toulouse, France). CO profiles are retrieved from $\sim 20 \mathrm{~km}$ to the lower thermosphere, with a typical resolution of $3 \mathrm{~km}$ throughout. The single-scan precision is 

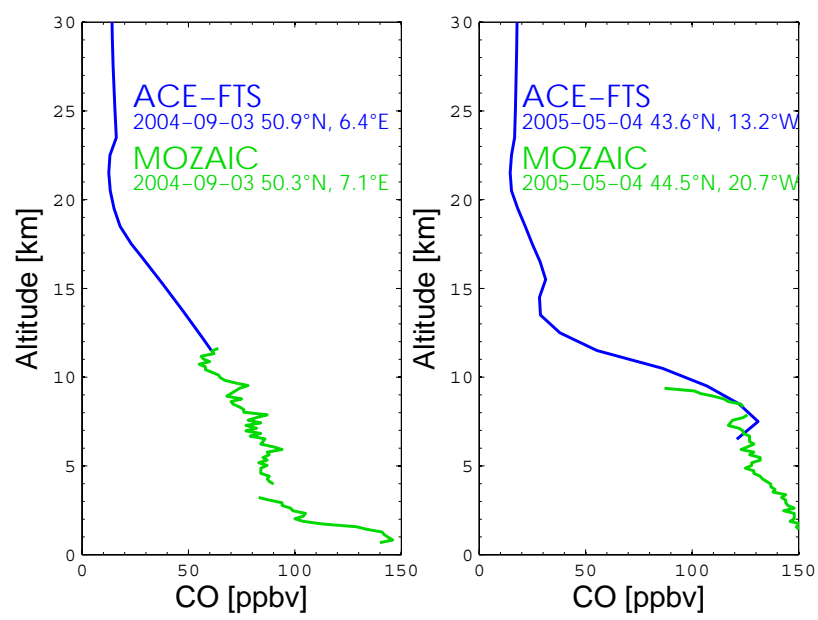

Fig. 12. Examples of co-located $\mathrm{CO}$ vertical mixing ratio profiles measured by ACE-FTS (blue) and by the MOZAIC airborne program (green). Note that the upper limit altitude of the MOZAIC measurement is often close to, or at the same altitude, as the ACEFTS lowest measured altitude.

estimated at better than $25 \mathrm{ppbv}$ in the stratosphere increasing up to $1-2 \mathrm{ppmv}$ at $\sim 80 \mathrm{~km}$ (Barret et al., 2006). The SMR CO measurements and data analysis methodology were described in detail by Dupuy et al. (2004). Early qualitative comparisons with ACE-FTS were published by Jin et al. (2005), whilst a detailed comparison of SMR/Odin with Aura/MLS can be found in Barret et al. (2006).

\subsubsection{MLS/Aura}

The Microwave Limb Sounder (MLS) (Waters, 2006) is one of four instruments on the EOS Aura satellite (Schoeberl et al., 2006) which was launched in July 2004. MLS is essentially a small radio telescope, viewing the Earth's limb in the orbit plane of the Aura satellite. Observations range from 82 degrees South to 82 degrees North every day and are spaced $140 \mathrm{~km}$ apart along the ground track. MLS detects thermally-emitted radiation in several bands of the sub-millimetre spectral region, at frequencies ranging from $118 \mathrm{GHz}$ to $2500 \mathrm{GHz}$. The measurements are processed to obtain profiles of temperature, geopotential height and the mixing ratio of more than 14 chemical species.

The mixing ratio of $\mathrm{CO}$ is obtained from measurements of the spectral line at $230 \mathrm{GHz}$. Two separate spectrometers are centred on this spectral line: a conventional filter bank of 25 channels and a digital autocorellator spectrometer (DACS) with 129 channels. The DACS channels are $97.6 \mathrm{kHz}$ wide giving a total width of $12.5 \mathrm{MHz}$. The conventional filter bank has channels of various widths ranging from $6 \mathrm{MHz}$ to $96 \mathrm{MHz}$, giving a total bandwidth of over $1 \mathrm{GHz}$. Version 2.2 data products are used for these comparisons. The MLS retrieval technique is described in detail by (Livesey et al.,

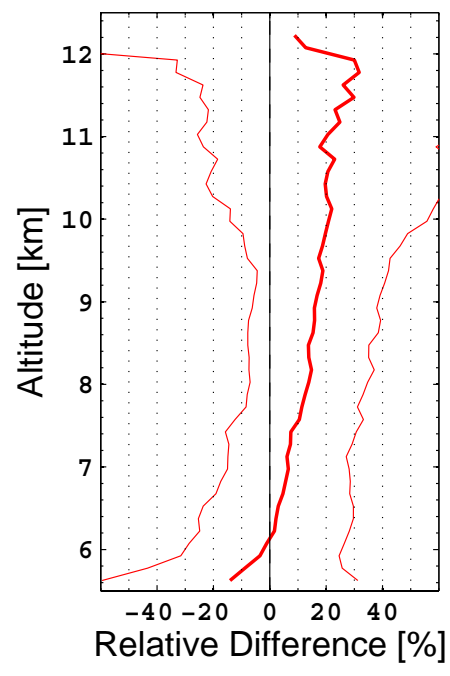

Fig. 13. Averaged percent difference between ACE-FTS and MOZAIC $\left(\mathrm{CO}_{\mathrm{ACE}}-\mathrm{CO}_{\mathrm{MOZAIC}} / 1 / 2\left(\mathrm{CO}_{\mathrm{ACE}}+\mathrm{CO}_{\mathrm{MOZAIC}}\right)\right)$, calculated using all the coincident observations (thick red line), along with the corresponding standard deviation (thin red lines) for the years 2004 and 2005. The number of coincident profiles ranges between 4 (at $12 \mathrm{~km}$ ) to 37 (at 8-9 km).

2006) and the validation of the $2.2 \mathrm{CO}$ product is provided in (Pumphrey et al., 2007).

\section{Validation results}

\subsection{Methodology used for the intercomparison}

All the data used in this paper were obtained from the teams that are working on the routine retrieval and analysis of $\mathrm{CO}$ concentrations for their measurement device, and who helped us to select the most reliable data for the validation comparisons. The coincidence location criteria (ACE-FTS versus instrument) and the $\mathrm{CO}$ product to compare (profile, smoothed profiles, or integrated partial columns) were decided in agreement with the participants, and after discussion with the people involved in the validation of the ACE-FTS products, for consistent analyses.

In this paper, we used the same procedure to treat all the measurements provided by the participating groups:

1. Select the data that meet the location and time coincidence criteria (see Table 3),

2. Intercompare ACE-FTS versus instrument at the altitude range where both instruments are simultaneously sensitive,

3. Convolve the ACE-FTS profile with the instrument averaging kernels when relevant (see text for discussion) to account for the different instrumental vertical sensitivities, 

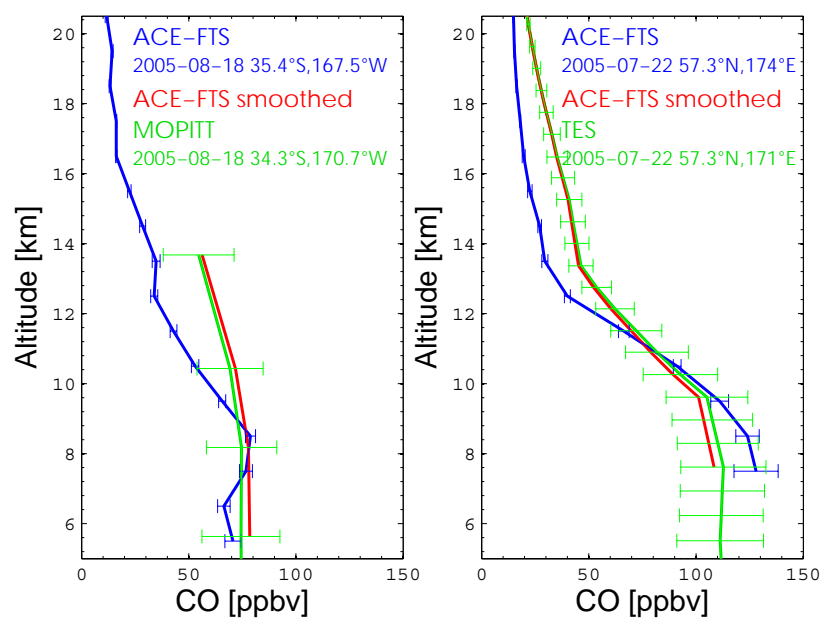

Fig. 14. Examples of co-located $\mathrm{CO}$ vertical mixing ratio profiles for ACE-FTS (blue) and two nadir-looking instruments (green): MOPITT (left) and TES (right). The retrieval errors are also reported (horizontal blue bars show ACE-FTS fitting errors from v2.2, and horizontal green bars at each retrieved level for the nadirlooking instrument). The red curve represents the convolution of the ACE-FTS profile with the averaging kernel function of the nadirviewing instrument.

4. Calculate the percent difference $\mathrm{CO}_{\mathrm{ACE}}{ }^{-}$ $\mathrm{CO}_{\text {instrument }} / 1 / 2\left(\mathrm{CO}_{\mathrm{ACE}}+\mathrm{CO}_{\text {instrument }}\right), \quad$ averaged over all the coincident observations, and the corresponding standard deviation,

5. Check if the co-location criteria used are stringent enough to sound similar air masses (for polar cases).

\subsection{Ground-based data}

A summary of the number of coincidences with ACEFTS occultation measurements (for which ACE-FTS CO retrievals were available) is given in Table 3 for each groundbased station, along with an indication of the vertical sensitivity of the observation and the associated accuracy. A more complete description of each station, instrument and $\mathrm{CO}$ retrieval setup (inversion algorithm used and spectroscopic databases) can be found in the above-mentioned references (Sect. 3.2). After some tests, the coincidence criteria were chosen such that the measurements were within $24 \mathrm{~h}$ and within $1000 \mathrm{~km}$. This ensured that there were at least a few matches per station. In case several ground-based profiles were available for one ACE occultation, the one that occurred closest in time was chosen. Figure 8 illustrates the time and location coincidences between the ACE occultation measurements and each of the ground based stations for February 2004-December 2006.

For the ground-based stations, the number of coincident CO observations was found to vary between 2 and 39, depending on the location of the station, the frequency of ACE-
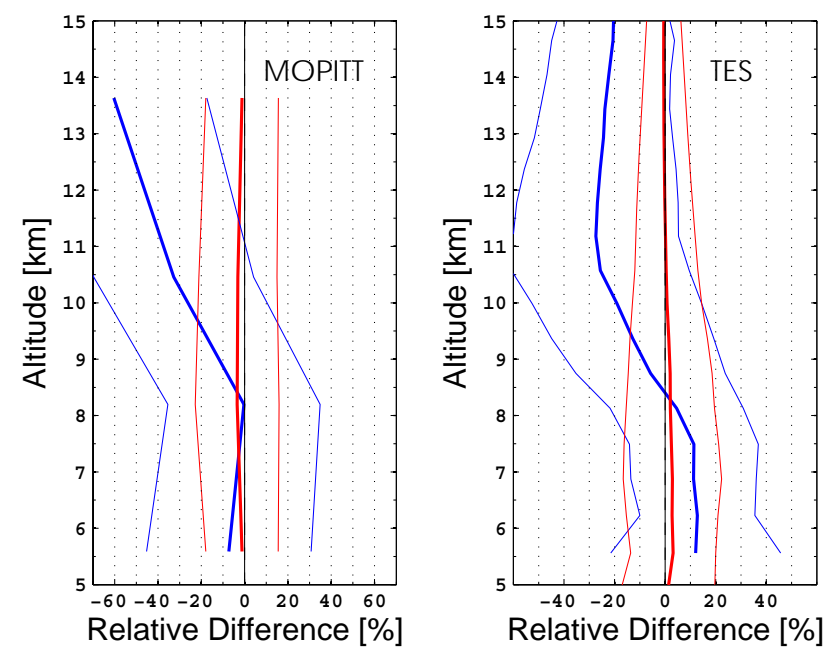

Fig. 15. Averaged percent difference $\left(\mathrm{CO}_{\mathrm{ACE}}{ }^{-}\right.$ $\left.\mathrm{CO}_{\text {nadir }} / 1 / 2\left(\mathrm{CO}_{\mathrm{ACE}}+\mathrm{CO}_{\text {nadir }}\right)\right)$, calculated using all the coincident observations (thick blue line), along with the corresponding standard deviation (thin blue lines) for the years 2004, 2005 and 2006 (left, MOPITT) and 2005-2006 (right, TES). The red lines are for the ACE-FTS profiles which are smoothed by the nadir sounder averaging kernel functions. For both instruments, the number of coincident profiles ranges between $\sim 850$ (at $6 \mathrm{~km}$ ) to $\sim 3400$ (above $12 \mathrm{~km}$ ).

FTS measurements at the latitude of the station and the cloud coverage. A smoothing of the ACE-FTS CO profiles was also performed according to Eq. (1), using the a priori profiles and averaging kernel functions provided along with the ground-based $\mathrm{CO}$ profile observations.

Figure 9 represents the averaged observations for the stations for which at least 20 co-located measurements were found, both with raw data and the smoothed ACE-FTS data. The direct comparison of profiles proved to be difficult (see percent difference in Fig. 9), as the ACE-FTS height range and vertical resolution differs strongly from that of the ground-based instruments. Although some individual profiles matched quite well, we decided, for the sake of consistency, to compare partial column values. These results are summarized as a scatterplot in Fig. 10. The integrated CO partial columns were calculated from the lowest altitude for which ACE-FTS CO results were available up to $25 \mathrm{~km}$, unless indicated otherwise in Table 3 . The density needed for the column calculations at the location of each measurement was obtained by interpolating the European Centre for Medium-Range Weather Forecasting (ECMWF) data in place and time. Table 4 summarizes the averaged percent relative difference and standard deviation per station. The averaged differences were found to range from $13 \%$ to $40 \%$. We found a very good correlation of 0.91 , although the data are scattered for high $\mathrm{CO}$ volume mixing ratio levels. The agreement has to be discussed keeping in mind the fact that the measurements are up to $1000 \mathrm{~km}$ apart and up to $24 \mathrm{~h}$ 


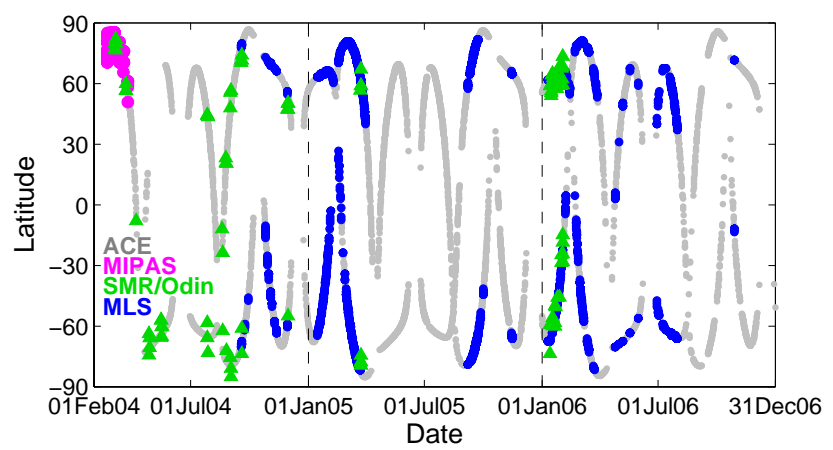

Fig. 16. Coincidences between the ACE-FTS measurement locations (in light gray, ACE occultation latitude versus time of the year) with the limb satellite measurements (MIPAS in magenta circles; SMR as green triangles; MLS in blue circles) in 2004, 2005 and 2006. The coincidence criteria are provided in Table 3 . Note that if time coincidences occur for a same station, symbols might be superposed.

later, so some variability in the $\mathrm{CO}$ content is to be expected.

When looking at Fig. 10 and Table 4, the largest disagreements and standard deviations are observed over stations located at very high latitudes and hence where measurements may sample different regions of the polar vortex. For observations at high latitudes that were measured close to or within the polar vortex, further investigation was performed in order to check if both the validation and the ACE-FTS instrument have sounded the same air masses. For these cases, potential vorticity (PV) maps in the region of both measurements were calculated using the MIMOSA contour advection model (Hauchecorne et al., 2002), on isentropic surfaces at $475 \mathrm{~K}(\sim 18 \mathrm{~km})$ and the air masses were compared. The data potentially coming from different air masses are flagged with a different symbol (star) in Fig. 10 and the calculations of relative differences in Table 4 are provided with and without accounting for these specific situations.

\subsection{Airborne data}

\subsubsection{SPIRALE (high altitude balloon)}

Only one coincidence (Fig. 11) was found with the SPIRALE balloon measurements and it occurred on 20 January 2006 between 17:32 UT and 19:47 UT. The CO volume mixing ratio profile was obtained during ascent, between 10.0 and $27.3 \mathrm{~km}$. The balloon measurement position remained rather constant, with a mean location of $67.6 \pm 0.2^{\circ} \mathrm{N}$ and $21.55 \pm 0.20^{\circ} \mathrm{E}$. The comparison is made with the ACEFTS sunrise occultation that occurred $13 \mathrm{~h}$ later (sr13151 on 21 January 2006 at 08:00 UT, $64.28^{\circ} \mathrm{N}, 21.56^{\circ} \mathrm{E}$ ) and $413 \mathrm{~km}$ away from the SPIRALE position.

Similar to what was performed for ground-based stations, a potential vorticity map was calculated from the MIMOSA contour advection model in the region of both measurements.
They show that SPIRALE and ACE-FTS sounded similar air masses within the well-established polar vortex for the whole range of altitudes. The dynamical situation was stable with the PV agreement obtained to better than $10 \%$. Even though ACE-FTS has a vertical resolution of $3-4 \mathrm{~km}$ and that of SPIRALE is more of the order of meters, smoothing the latter data with a set of triangular convolution functions (each $3 \mathrm{~km}$ at the base corresponding to the ACE resolution) did not change the shape of the SPIRALE CO profile.

For CO, the SPIRALE total uncertainty is estimated to be $6 \%$ over the entire altitude range. As shown in Fig. 11, the agreement is better than $22 \%$ between SPIRALE and ACE-FTS profiles for the altitude range $14-20 \mathrm{~km}$. Between 20 and $24 \mathrm{~km}$, the ACE-FTS profile is lower than SPIRALE by $36-120 \%$. Above $24 \mathrm{~km}$, the ACE-FTS profile becomes larger than SPIRALE with relative differences reaching $120 \%$ around $26-27 \mathrm{~km}$. Although the SPIRALE instrument is providing more accurate measurements than ACEFTS, it is difficult to draw conclusions based on a single winter profile located $400 \mathrm{~km}$ away and measured within the polar vortex. The ACE-FTS high positive values around $27 \mathrm{~km}$ might also be related to the negative ones around $23 \mathrm{~km}$.

\subsubsection{MOZAIC (airplane)}

The CO measurements recorded during the MOZAIC commercial flights in 2004 and 2005 were compared with the ACE-FTS data. The collocation criteria, within $24 \mathrm{~h}$ and within a geographic distance of $\pm 9^{\circ}$ latitude and $\pm 10^{\circ}$ longitude, provided 108 matches. As there is only a small height range (localized between 6 and $12 \mathrm{~km}$ ) where the CO measurements from both instruments overlap, we added an extra constraint such that at least three $\mathrm{km}$ of common observations should exist. The number of available co-located observations then decreased to 39 . Figure 12 illustrates two typical examples where the highly resolved MOZAIC CO profiles connect well with the ACE-FTS data. Figure 13 summarizes comparisons between the two datasets for 2004 and 2005, by plotting the average of the percentage relative difference between the coincident ACE-FTS and MOZAIC data. The standard deviation of the differences is also provided, along with the number of data points used at each altitude. The agreement is very good, as the averaged difference is found to be lower than $16 \%$ between 6 and $12 \mathrm{~km}$, in 2004-2005, with a positive bias. A parallel work performed with other airborne data (Hegglin et al., 2008) reports a 10\% agreement for $\mathrm{CO}$ in the same altitude range.

\subsection{Nadir-viewing satellites: MOPITT/Terra and TES/Aura}

The MOPITT and TES nadir-viewing instruments provide global measurements using the thermal infrared emission of the Earth and the atmosphere to measure $\mathrm{CO}$ vertical profiles. As these two instruments have a small horizontal pixel 

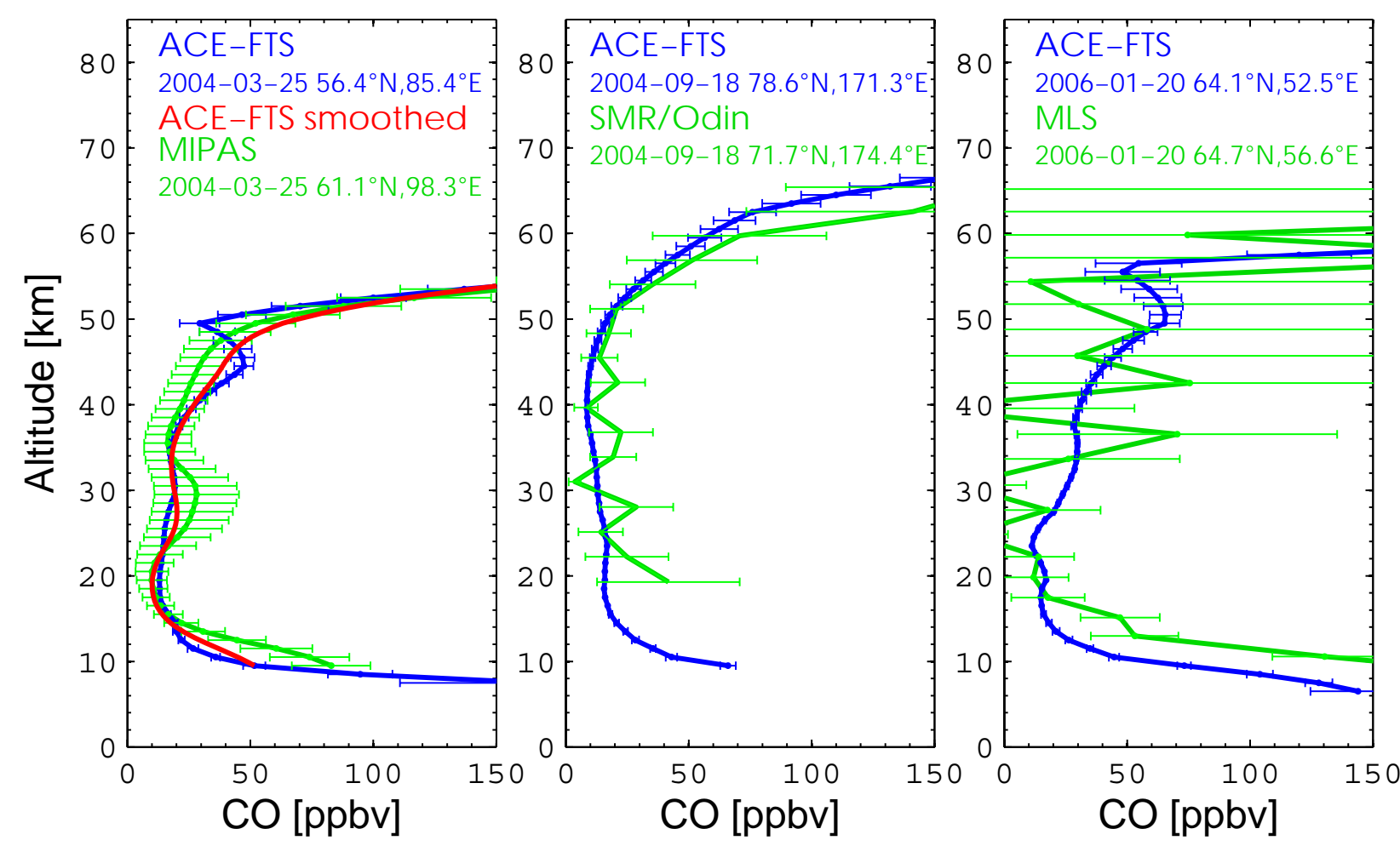

Fig. 17. Examples of co-located CO vertical mixing ratio profiles for ACE-FTS (blue) and three limb-looking instruments (MIPAS, SMR and MLS; in green). The retrieval errors are also reported (horizontal blue bars for ACE-FTS fitting errors from v2.2 files, and horizontal green bars for each limb-instrument). As MIPAS data are less vertically resolved, the ACE-FTS profile was smoothed by the MIPAS averaging kernels (in red).

Table 5. Summary of percent average difference on partial columns for the validation instruments, as a function of altitude, using (100 $\mathrm{x}$ $\left(\mathrm{CO}_{\mathrm{ACE}}-\mathrm{CO}_{\text {Instru }}\right) / 1 / 2\left(\mathrm{CO}_{\mathrm{ACE}}+\mathrm{CO}_{\text {Instru }}\right)$. When a smoothing was applied, data are provided in italics.

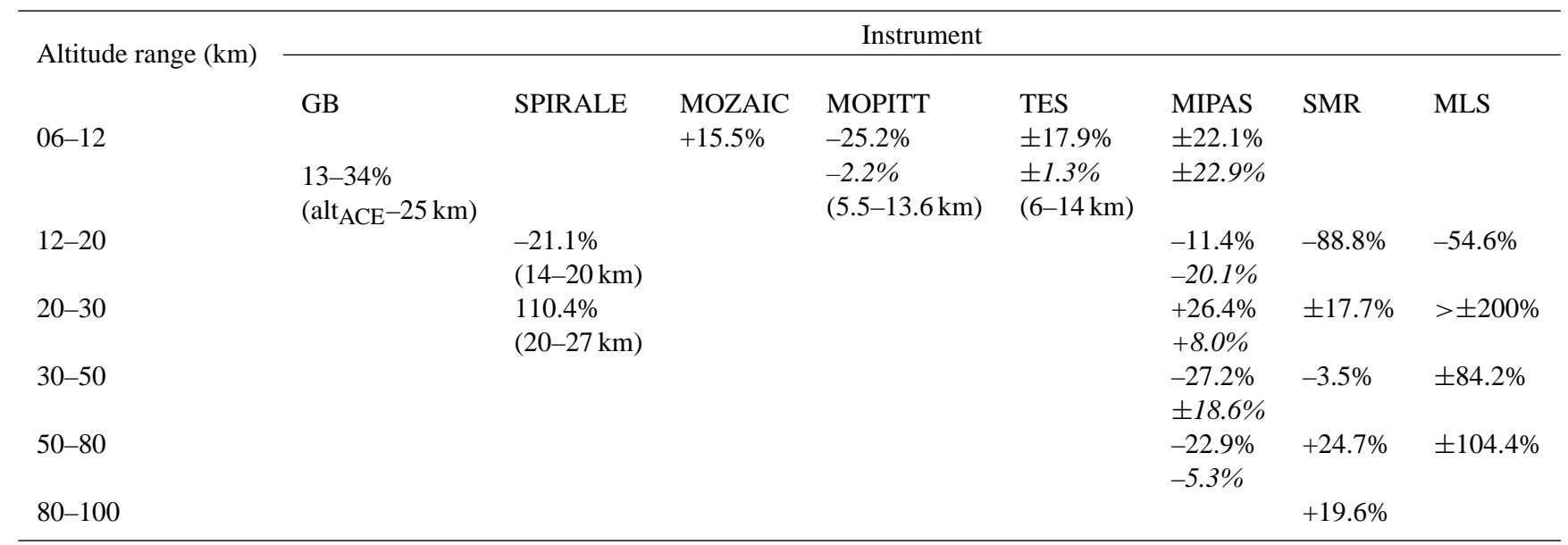



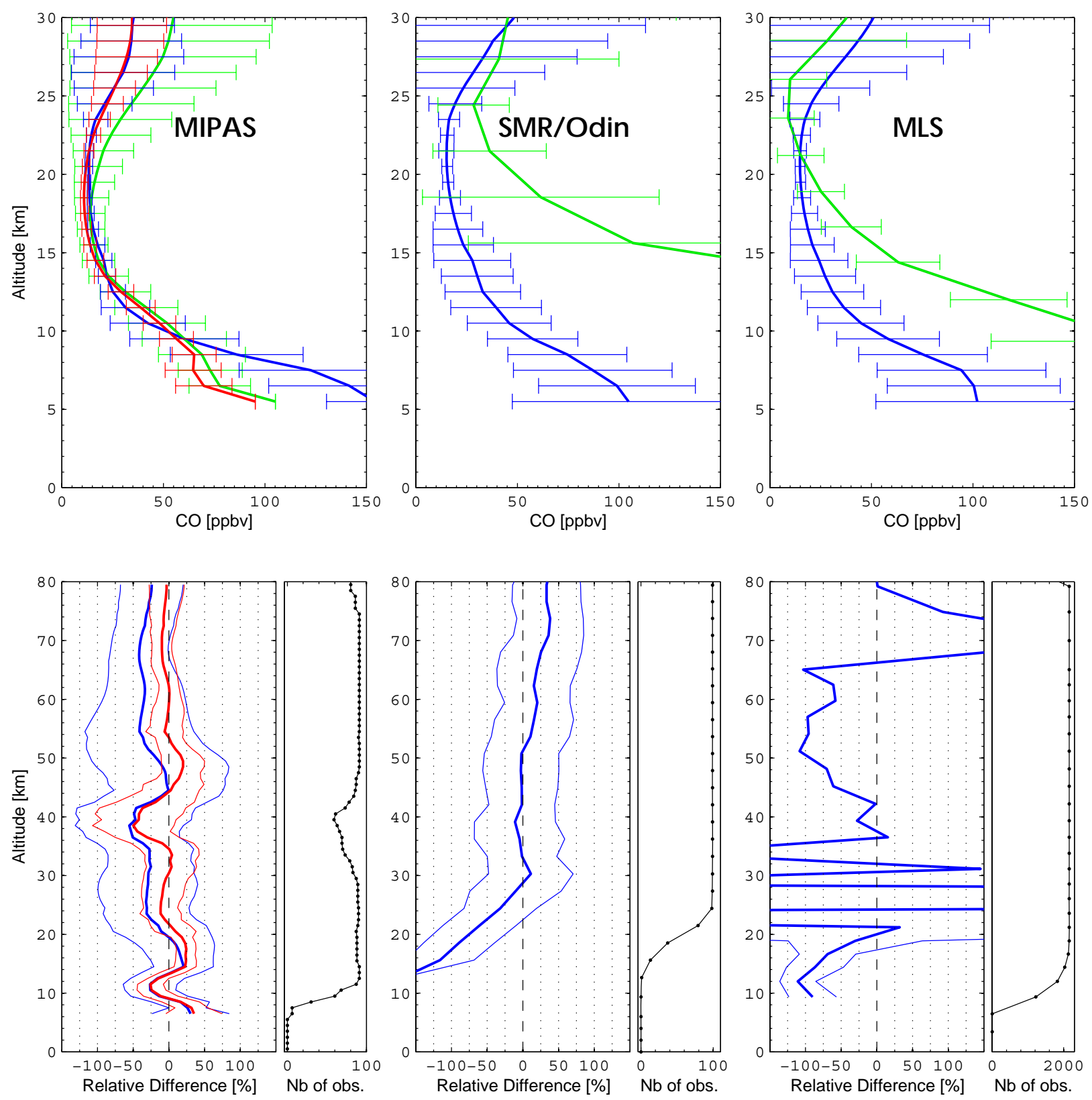

Fig. 18. Top panel: CO mixing ratio profiles, averaged over all the coincident observations, for ACE-FTS (blue) and three limb-viewing instruments (in green). The standard deviations are plotted as horizontal bars. ACE-FTS smoothed by the MIPAS averaging kernel functions is plotted in red. Bottom panel: Averaged percent difference $\left(\mathrm{CO}_{\mathrm{ACE}}-\mathrm{CO}_{\text {limb }} / 1 / 2\left(\mathrm{CO}_{\mathrm{ACE}}+\mathrm{CO}_{\text {limb }}\right)\right.$, thick lines $)$, along with the corresponding standard deviation (thin lines) for MIPAS (before and after smoothing ACE-FTS, in blue and red respectively), SMR and MLS. The number of data points included in the average, as a function of altitude, is also provided as sub-plots.

size and global coverage, coincidences with the ACE-FTS occultation measurements are numerous. This study was performed using the following criteria: same day and within $5^{\circ}$ longitude, $5^{\circ}$ latitude for MOPITT (version 3), and $\pm 24 \mathrm{~h}$, within $300 \mathrm{~km}$ for TES (version V002). The choice of the coincidence criteria depended on how the data products are stored for each mission. For both instruments more than 3000 cases were found, spanning 2004, 2005 and 2006.

As with every thermal infrared nadir-sounding instrument, TES and MOPITT lack sensitivity near the surface due to the small thermal contrast between the Earth's skin temperature and the first atmospheric levels, and the observations 
they provide have a limited vertical resolution. Although the $\mathrm{CO}$ volume mixing ratio products are provided at several altitudes, the levels are strongly correlated and the number of pieces of independent information ranges between one (total column) and two (two partial columns), depending on the latitude, with a maximum sensitivity in the free troposphere and information up to about $16 \mathrm{~km}$. As discussed in Luo et al. (2007a), both MOPITT and TES CO retrieved profiles are biased by their a priori; but when similar initial conditions are considered, TES and MOPITT agree reasonably $(<5 \%$ global average with $<20 \%$ root mean squares for individual cases). Accuracies for both instruments were estimated to be $10 \%$ using aircraft data (Emmons et al., 2004; Luo et al., $2007 \mathrm{~b}$ ), in places where the retrievals are not influenced by the a priori.

Interestingly, as MOPITT and TES both have their maximum sensitivity around $6-8 \mathrm{~km}$, a useful comparison can be obtained in the upper troposphere. In order to account for the different vertical sensitivities in the comparisons, the ACE-FTS profiles have been smoothed using the corresponding MOPITT and TES characteristics and Eq. (1). Figure 14 shows one MOPITT/ACE-FTS and one TES/ACE-FTS example comparison of co-located profiles used in the validation exercise. It can be seen that, here again, we have only a few altitude levels in common between the measurements (ACE-FTS profiles start no lower than $5 \mathrm{~km}$ ). As expected, when looking at the paired sets of observations, the ACEFTS CO profiles show much more vertical variability, with often the $5-10 \mathrm{~km} \mathrm{CO}$ mixing ratios being higher, and the 10-20 km CO mixing ratio being lower than the MOPITT or TES ones. As can be observed from Fig. 14, the smoothed ACE-FTS profiles match the nadir viewing observations very well. Figure 15 provides the mean and standard deviation results averaged for the thousands of coincident profiles studied for the period 2004-2006. For both instruments, without smoothing, the agreement is around $10 \%$ between 5.5 and $8.5 \mathrm{~km}$, and the disagreement increases with a negative bias of -10 to $-60 \%$ for MOPITT and around $-25 \%$ for TES in the range 9 to $15 \mathrm{~km}$. As MOPITT relies on a single global a priori whereas TES uses different latitude-varying a priori, we expected to find higher differences in the case of MOPITT. After convolution with the averaging kernels associated with each instrument, we have an almost perfect match (less than $2.2 \%$ discrepancy in the $5.5-15 \mathrm{~km}$ altitude range). Differences in retrieval diurnal sensitivity are also accounted for this way.

\subsection{Limb-viewing satellites: MIPAS/Envisat, SMR/Odin and MLS/Aura}

There are currently three spaceborne instruments providing regular CO measurements using limb geometry: MIPAS/Envisat (Funke et al., 2007), SMR/Odin (Barret et al., 2006) and MLS/Aura (Filipiak et al., 2005). As for ACE, these missions are not able to see the lowest layers of the
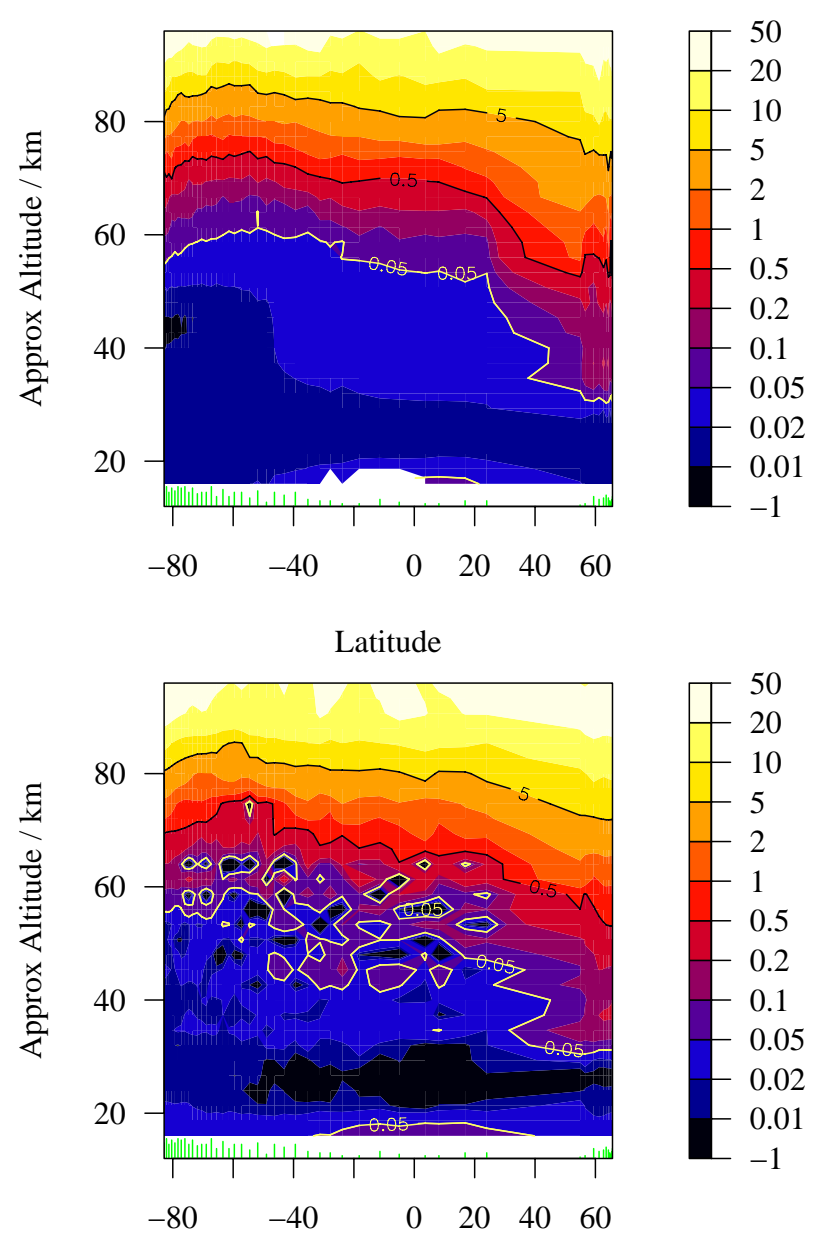

Latitude

Fig. 19. ACE-FTS (top) and MLS (bottom) CO mixing ratios (ppmv) for 2 September-13 October 2006. For ACE-FTS the sunset latitude moves northwards during this period, so 2 September is at the left-hand side of the Figure. The ticks near the bottom of the Figure show the mean ACE-FTS latitude for each of the days plotted; the length of each tick is proportional to the number of ACE-FTS sunset profiles on that day. For each ACE-FTS sunrise profile we took the 5 closest collocated MLS profiles and average together all such profiles for the day, in order to reduce noise. The data have been smoothed in latitude, with a smoothing length of $3^{\circ}$.

atmosphere due to the increase in atmospheric opacity and occurance of clouds.

A detailed validation study of SMR versus MLS is found in (Barret et al., 2006), and a detailed comparison of MLS $\mathrm{CO}$ results with other instruments is provided in (Pumphrey et al., 2007).

For each of the three instruments, the time and location coincidence criteria were carefully chosen in agreement with the participants (see Table 3 for the summary). Figure 16 illustrates the ACE latitudinal coverage as a function of the time with the coincidences associated with each limb 
instrument indicated. When several observations matched the same ACE-FTS profile, we selected the closest in time.

For MIPAS, the CO measurements available (version 9.0) just overlapped with the beginning of the ACE mission. By the end of March 2004, MIPAS operation was suspended due to instrumental problems. MIPAS resumed its measurements by the beginning of 2005 , however, with reduced spectral resolution. For comparison with ACE-FTS, only the high-resolution data are chosen. In the MIPAS sensitive range $(10-70 \mathrm{~km})$, the vertical resolution varies between 6 and $12 \mathrm{~km}$, depending on altitude region and illumination conditions. The estimated precision is $10-30 \%$ except for the $20-45 \mathrm{~km}$ region with values around $30-70 \%$. The accuracy is limited mainly by instrumental noise. Model errors due to uncertainties in the non-LTE modelling have been estimated to be less than $10 \%$ (Funke et al., 2007). During the February and March 2004 period, using a coincidence criterion of ( $\pm 18 \mathrm{~h}, \pm 1000 \mathrm{~km})$, about 100 matches were found. It is worth noting that a very strong polar vortex occurred in the 2004 Arctic winter, leading to downwelling of large amounts of $\mathrm{CO}$ into the upper stratosphere. The convolution of ACE-FTS profiles with MIPAS averaging kernel functions was found to be necessary, as MIPAS vertical resolution is lower than that of ACE-FTS, in particular during night and above $40 \mathrm{~km}$.

For SMR CO observations, we used the data (CTSO, version 225) as described in Barret et al. (2006), with the following coincidence criteria: $\pm 10 \mathrm{~h}, \pm 9^{\circ}$ latitude and $\pm 10^{\circ}$ longitude. A quality filter to select the more reliable data (good convergence and measurement response over $75 \%$ ) led to 99 coincidences, with a vertical sensitivity from $\sim 20$ to $95-100 \mathrm{~km}$, and an average vertical resolution of $\sim 3 \mathrm{~km}$.

The largest set of validation data is provided by the MLS/Aura instrument. More than 2100 coincidences were found using the following criteria: same day, $\pm 0.75^{\circ}$ latitude, $\pm 12^{\circ}$ longitude. Following the recommendations from Pumphrey et al. (2007), the MLS data (version 2.2.) were filtered using the following values for internal checks: L2gpPrecision $>0$; and Quality $>0.2$; and Status $<126$; and Convergence $<1.8$. The vertical sensitivity of MLS ranges from 10 to $85 \mathrm{~km}$, with 3-4 km vertical resolution over most of this range.

Typical CO profiles for each limb-viewing instrument are compared with the corresponding ACE-FTS CO data in Fig. 17. In general, the agreement per set of profiles is reasonable, depending on the altitude level considered. The ACE-FTS CO profiles are usually smoother than SMR and MLS (see Pumphrey et al., 2007 for further discussion), but the ACE-FTS v2.2 sometimes show oscillations (with even negative values) around $40-50 \mathrm{~km}$, which might lead to large discrepancies when comparing with the other limb instruments at these altitudes.

Figure 18 provides the averaged profiles, the relative differences, the standard deviations and the number of coincidences per altitude, over the whole data set for each instru- ment. When looking at the relative difference plots, for MIPAS (Fig. 18, bottom left plot) the agreement is very good. After smoothing with the averaging kernel, the differences between the convolved ACE-FTS and MIPAS profiles (red line) are within $\pm 26 \%$ at all altitudes, except between 38 and $41 \mathrm{~km}$ where it reaches $-50 \%$. These differences are linked to the very unusual situation of strong CO-downward transport in the Artic polar vortex in 2004, where most of the coincidences between ACE-FTS and MIPAS are located. When all the data above $70^{\circ} \mathrm{N}$ are filtered out, the differences were found to be further reduced (not shown here), but the number of coincident data decreased from 99 to 27 .

SMR CO mixing ratios (Fig. 18, bottom middle plot) are considerably larger than those of ACE-FTS (by more than $50 \%$ ) below $\sim 22 \mathrm{~km}$. Between 25 and $68 \mathrm{~km}$, we found a very good agreement as the difference does not exceed $25 \%$. Above $60 \mathrm{~km}$, the ACE-FTS mixing ratios become larger than the SMR values.

For MLS, we found a negative bias below $20 \mathrm{~km}$, large oscillating discrepancies between 20 and $35 \mathrm{~km}$, a good agreement between 38 and $42 \mathrm{~km}$, a negative bias ranging from $-25 \%$ to $-100 \%$ from 42 to $65 \mathrm{~km}$, and a strong positive bias between 65 and $80 \mathrm{~km}$.

Several studies comparing CO measured by the ACE-FTS, SMR and MLS limb sounders have already been published (Froidevaux et al., 2006; Barret et al., 2006; Pumphrey et al., 2007). Our results are broadly consistent with those studies however the plots might look different because we used $1 / 2$ $\left(\mathrm{CO}_{\mathrm{ACE}}+\mathrm{CO}_{\text {limb }}\right)$ to calculate the relative values, instead of $\left(\mathrm{CO}_{\text {limb }}\right)$ as was used in the above-mentioned papers. In the upper troposphere (below $20 \mathrm{~km}$ ), we found that ACE-FTS CO profiles are much lower than those of MLS and SMR, in agreement with the results from Pumphrey et al. (2007) who have compared MLS version 2.2 and ACE-FTS CO. Livesey et al. (2008) also show that MLS CO is a factor of 2 too high at the $215 \mathrm{hPa}$ retrieval level by comparison with MOZAIC airborne in situ data. In the lower stratosphere (below $30 \mathrm{~km}$ ) ACE-FTS exhibits an underestimation of CO relative to MLS which is consistent with Pumphrey at al. (2007) and Froidevaux et al. (2006). Barret et al. (2006) reported an underestimation of MLS CO relative to SMR, especially in the tropics, at these altitudes.

Two dimensional latitude/altitude comparison plots for ACE-FTS and MLS are provided in Fig. 19, similar to what was reported in (Pumphrey et al., 2007). We display the ACE-FTS and coincident MLS data by taking a series of ACE-FTS measurements over latitudes moving from south to north between 2 September and 13 October, and plotting the mean daily profiles. To reduce noise, we averaged the closest MLS profiles to each ACE-FTS profile. Although the MLS data are more noisy and ragged, particularly near 45$60 \mathrm{~km}$, it is clear that there are many similarities between the two datasets. We note in particular the high volume mixing ratios in the southern polar vortex. The biases between the two instruments can also be seen. 


\section{Summary and conclusions}

This paper provides an assessment of the $\mathrm{CO}$ atmospheric profiles obtained during the first three years of the ACE mission, in order to quantify the level of agreement obtained with other available instruments. The ACE-FTS CO version 2.2 products are derived from solar occultation measurements, using two $\mathrm{CO}$ absorption bands located around $2100 \mathrm{~cm}^{-1}$ and $4250 \mathrm{~cm}^{-1}$, which allows sounding the atmosphere from about $5 \mathrm{~km}$ up to $100 \mathrm{~km}$. The vertical sampling ranges from 2 to $6 \mathrm{~km}$, depending on the altitude and on the beta angle of the measurement. Although the horizontal coverage of ACE-FTS is limited by the solar occultation mode, when accumulating several months of measurements we show that interesting features can be studied in the mid-troposphere (transport of pollution plumes associated with pollution and biomass burning events), in the UTLS (convection over tropical regions) and in the stratosphere-mesosphere (descent of $\mathrm{CO}$-rich air masses over the winter poles).

A comprehensive validation exercise was undertaken that involved the simultaneous analysis of partial column data derived from the routine profile observations from eleven ground-based stations, of profiles derived from balloon borne and aircraft observations, and of vertical distributions as measured by the available nadir and limb-looking satellites. For each instrument, we carefully selected the coincident and most reliable data products to intercompare (partial columns or part of vertical profiles). When required, an additional data processing step or constraint was added such as convolution with the averaging kernel functions, or sorting based on PV for high latitude ground-based stations.

The intercomparison of the ACE-FTS CO profiles at all altitude levels proved to be difficult as none of the correlative instruments provide measurements that cover the full range of the ACE measurements. A summary of the averaged percent differences, as a function of altitude, for all the instruments included in this validation paper, is provided in Table 5. In the mid to upper troposphere, we were able to compare the ACE-FTS CO data with partial columns provided by ground-based data, with the highly resolved profiles provided by MOZAIC (aircraft), and with the nadir observations from the MOPITT and TES nadir-looking instruments. For the latter, the agreement is excellent when the averaging kernel information is taken into account, although these results should be tempered by the fact that there is not much more than one piece of information available from the nadirviewing satellite observations. As the maximum sensitivity of both TES and MOPITT are around the altitude of the first levels of the ACE-FTS CO observation, we can conclude that the ACE-FTS CO products are reliable between 6 and $10 \mathrm{~km}$, with an agreement reaching $2.5 \%$ at these altitudes. We report a good agreement with the MOZAIC $(15 \%$ on average between 6 and $12 \mathrm{~km}$ ) and SPIRALE (around $25 \%$ or better below $20 \mathrm{~km}$ ) measurements, despite the loose coincidence criteria. The comparison of partial columns retrieved by
ACE-FTS with partial columns retrieved from ground-based FTIR data at several locations revealed differences ranging between 13 and 34\% when adequate smoothing is applied, with no systematic bias and standard deviations between 7 and $28 \%$. The causes of the disagreement could be linked to atmospheric variability. In the stratosphere, from about 12 to $50 \mathrm{~km}$, where the CO levels are usually very low, large discrepancies were found with SPIRALE balloon observation but it relies on one single coincident measurement in polar vortex conditions. From 20 to $100 \mathrm{~km}$, comparisons performed with limb sounders show an agreement better than $30 \%$, except for MLS. For the latter, individual profiles were found to be much noisier than the ACE-FTS data, but when averaged over longer time period and latitudes the $\mathrm{CO}$ atmospheric features agree well (Fig. 19). From these findings, combined with our initial estimation of the ACE-FTS retrieval errors, we assigned the following uncertainties to the ACE-FTS measurement data: better than $15 \%$ in the upper troposphere $(8-12 \mathrm{~km})$, than $30 \%$ in the lower stratosphere $(12-30 \mathrm{~km})$, and than $25 \%$ from 30 to $100 \mathrm{~km}$.

Acknowledgements. The Atmospheric Chemistry Experiment (ACE), also known as SCISAT-1, is a Canadian-led mission mainly supported by the Canadian Space Agency (CSA) and the Natural Sciences and Engineering Research Council of Canada. Odin is a Swedish-led satellite project funded jointly by Sweden (SNSB), Canada (CSA), France (Centre National d'Etudes Spatiales, CNES) and Finland (Tekes). C. Clerbaux and S. Turquety are grateful to CNES for financial support. We thank Matthieu Pommier and Catherine Wespes for their contributions. The research in Belgium was funded by the F.R.S.-FNRS (M.I.S. $n^{\circ}$ F.4511.08), the Belgian State Federal Office for Scientific, Technical and Cultural Affairs and the European Space Agency (ESA-Prodex arrangements s C90-219). Financial support by the "Actions de Recherche Concertées" (Communauté Française de Belgique) is also acknowledged. ULg group members acknowledge that the International Foundation High Altitude Research Stations Jungfraujoch and Gornergrat (HFSJG), 3012 Bern, Switzerland, made it possible for us to carry out our experiments at the High Altitude Research Station at Jungfraujoch. The ground-based FTIR (and MW) data used in this publication were obtained as part of the Network for the Detection of Atmospheric Composition Change (NDACC). Data from these stations is publicly available from http://www.ndacc.org. SMR/Odin and MOZAIC data are stored in the Ether French atmospheric data base (http://ether.ipsl.jussieu.fr). Work at the Toronto Atmospheric Observatory was supported by NSERC, CFCAS, ABB Bomem, ORDCF, PREA, the University of Toronto, and a grant from the Canadian Space Agency. The SPIRALE balloon measurements could only be performed thanks to the technical team (L. Pomathiod, B. Gaubicher, G. Jannet); the flight was funded by ESA and CNES for the Envisat validation project; the CNES balloon launching team is greatly acknowledged for successful operations. The IAA team was supported by the Spanish project ESP2004-01556 and EC FEDER funds. The elements of the research described in this publication carried out at the Jet Propulsion Laboratory, California Institute of Technology, were under a contract with the National Aeronautics and Space Administration. The National Center for Atmospheric Research 
is sponsored by the National Science Foundation and operated by the University Corporation for Atmospheric Research. The NCAR FTIR observation program at Thule, GR is supported under contract by the National Aeronautics and Space Administration (NASA).

Edited by: T. Wagner

\section{References}

Barret, B., De Mazière, M., and Mahieu, E.: Ground-based FTIR measurements of $\mathrm{CO}$ from the Jungfraujoch: characterisation and comparison with in situ surface and MOPITT data, Atmos. Chem. Phys., 3, 2217-2223, 2003,

http://www.atmos-chem-phys.net/3/2217/2003/.

Barret, B., Ricaud, P., Santee, M. L., Attie, J. L., Urban, J., Le Flochmoen, E., Berthet, G., Murtagh, D., Eriksson, P., Jones, A., De La Noë, J., Dupuy, E., Froidevaux, L., Livesey, N. J., Waters, J. W., and Filipiak, M. J.: Intercomparisons of trace gases profiles from the Odin/SMR and Aura/MLS limb sounders, J. Geophys. Res., 111, D21302, doi:10.1029/2006JD007305, 2006.

Beer, R.: TES on the Aura mission: scientific objectives, measurements, and analysis overview, IEEE T. Geosci. Remote, 44, 1102-1105, 2006.

Bernath, P. F., McElroy, C. T., Abrams, M. C., Boone, C. D., Butler, M., Camy-Peyret, C., Carleer, M., Clerbaux, C., Coheur, P.-F., Colin, R., DeCola, P., De Mazière, M., Drummond, J. R., Dufour, D., Evans, W. F. J., Fast, H., Fussen, D., Gilbert, K., Jennings, D. E., Llewellyn, E. J., Lowe, R. P., Mahieu, E., McConnell, J. C., McHugh, M., McLeod, S. D., Midwinter, C., Nassar, R., Nichitiu, F., Nowlan, C., Rinsland, C. P., Rochon, Y. J., Rowlands, N., Semeniuk, K., Simon, P., Skelton, R., Sloan, J. J., Soucy, M.-A., Strong, K., Tremblay, P., Turnbull, D., Walker, K. A., Walkty, I., Wardle, D. A., Wehrle, V., Zander R., and Zou, J.: Atmospheric Chemistry Experiment (ACE): mission overview, Geophys. Res. Lett., 32, L15S01, doi:10.1029/2005GL022386, 2005.

Blumenstock, T., Kopp, G., Hase, F., Hochschild, G., Mikuteit, S., Raffalski, U., and Ruhnke, R.: Observation of unusual chlorine activation by ground-based infrared and microwave spectroscopy in the late Arctic winter 2000/01, Atmos. Chem. Phys, 6, 897905, 2006.

Boone, C. D., Nassar, R., Walker, K. A., Rochon, Y., McLeod, S. D., Rinsland, C. P., and Bernath, P. F.: Retrievals for the Atmospheric Chemistry Experiment Fourier Transform Spectrometer, Appl. Optics, 44, 7218-7231, 2005.

Clerbaux, C., Hadji-Lazaro, J., Payan, S., Camy-Peyret, C., Wang, J., Edwards, D., and Luo, M.: Retrieval of CO from nadir remotesensing measurements in the infrared by use of four different inversion algorithms, Appl. Optics, 41, 33, 7068-7078, 2002.

Clerbaux, C., Gille, J., and Edwards, D.: New Directions: Infrared measurements of atmospheric pollution from space, Atmos. Environ., 38, 27, 4599-4601, doi:10.1016/j.atmosenv.2004.05.005, 2004.

Clerbaux, C., Coheur, P.-F., Hurtmans, D., Barret, B., Carleer, M., Colin, R., Semeniuk, K., McConnell, J. C., Boone, C., and Bernath, P.: Carbon monoxide distribution from the ACEFTS solar occultation measurements, Geophys. Res. Lett., 32, L16S01, doi:10.1029/2005GL022394, 2005.
Clerbaux, C., Hadji-Lazaro, J., Turquety, S., George, M., Coheur, P.-F., Hurtmans, D., Wespes, C., Herbin, H., Blumstein, D., Tournier, B., and Phulpin, T.: The IASI/MetOp mission: first observations and highlight of its potential contribution to the GMES Earth observation component, Space Research Today (COSPAR Inf. Bul.), 168, 19-24, 2007.

Clerbaux, C., Edwards, D. P., Deeter, M., Emmons, L., Lamarque, J-F., Tie, X. X., Massie, S. T., and Gille, J.: Carbon monoxide pollution from cities and urban areas observed by the Terra/MOPITT mission, Geophys. Res. Lett, 35, L03817, doi:10.1029/2007GL032300, 2008.

Coheur, P.-F., Herbin, H., Clerbaux, C., Hurtmans, D., Wespes, C., Carleer, M., Turquety, S., Rinsland, C. P., Remedios, J., Hauglustaine, D., Boone, C. D, and Bernath, P. F.: ACE-FTS observation of a young biomass burning plume: first reported measurements of $\mathrm{C}_{2} \mathrm{H}_{4}, \mathrm{C}_{3} \mathrm{H}_{6} \mathrm{O}, \mathrm{H}_{2} \mathrm{CO}$ and PAN by infrared occultation from space, Atmos. Chem. Phys., 7, 5437-5446, 2007, http://www.atmos-chem-phys.net/7/5437/2007/.

Deeter, M. N., Emmons, L. K., Francis, G. L., Edwards, D. P., Gille, J. C., Warner, J. X., Khattatov, B., Ziskin, D., Lamarque, J.-F., Ho, S.-P., Yudin, V., Attié, J.-L., Packman, D., Chen, J., Mao, D., and Drummond, J. R.: Operational carbon monoxide retrieval algorithm and selected results for the MOPITT instrument, J. Geophys. Res., 108(D14), 4399, doi:10.1029/2002JD003186, 2003.

Deeter, M. N., Emmons, L. K., Edwards, D. P., Gille, J. C., and Drummond, J. R.: Vertical resolution and information content of CO profiles retrieved by MOPITT, Geophys. Res. Lett., 31, 15, L15112, doi:10.1029/2004GL020235, 2004.

de Zafra, R. L. and Muscari, G.: CO as an important high-altitude tracer of dynamics in the polar stratosphere and mesosphere, J. Geophys. Res., 109, D06105, doi:10.1029/2003JD004099, 2004.

Dils, B., De Mazière, M., Müller, J. F., Blumenstock, T., Buchwitz, M., de Beek, R., Demoulin, P., Duchatelet, P., Fast, H., Frankenberg, C., Gloudemans, A., Griffith, D., Jones, N., Kerzenmacher, T., Kramer, I., Mahieu, E., Mellqvist, J., Mittermeier, R. L., Notholt, J., Rinsland, C. P., Schrijver, H., Smale, D., Strandberg, A., Straume, A. G., Stremme, W., Strong, K., Sussmann, R., Taylor, J., van den Broek, M., Velazco, V., Wagner, T., Warneke, T., Wiacek, A., and Wood, S.: Comparisons between SCIAMACHY and ground-based FTIR data for total columns of $\mathrm{CO}, \mathrm{CH}_{4}, \mathrm{CO}_{2}$ and $\mathrm{N}_{2} \mathrm{O}$, Atmos. Chem. Phys., 6, 1953-1976, 2006,

http://www.atmos-chem-phys.net/6/1953/2006/.

Dufour, G., Szopa, S., Hauglustaine, D. A., Boone, C. D., Rinsland, C. P., and Bernath, P. F.: The influence of biogenic emissions on upper-tropospheric methanol as revealed from space, Atmos. Chem. Phys., 7, 6119-6129, 2007, http://www.atmos-chem-phys.net/7/6119/2007/.

Dupuy, E., Urban, J., Ricaud, P., Le Flochmoën, E., Lautié, N., Murtagh, D., de la Noë, J., El Amraoui, L., Eriksson, P., Forkman, P., Frisk, U., Jégou, F., Jiménez, C., and Olberg, M.: Stratomesospheric measurements of carbon monoxide with the Odin Sub-Millimetre Radiometer: Retrieval and first results, Geophys. Res. Lett., 31, L20101, doi:10.1029/2004GL020558, 2004.

Edwards, D. P., Emmons, L. K., Hauglustaine, D. A., Chu, A., Gille, J. C., Kaufman, Y. J., Pétron, G., Yurganov, L. N., Giglio, L., Deeter, M. N., Yudin, V., Ziskin, D. C., Warner, J., Lamarque, J.F., Francis, G. L., Ho, S. P., Mao, D., Chan, J., and Drummond, J. R.: Observations of Carbon Monoxide and Aerosol From the Terra Satellite: Northern Hemisphere Variability, J. Geophys. 
Res., 109, D24202, doi:10.1029/2004JD0047272004, 2004.

Edwards, D. P., Emmons, L. K., Gille, J. C., Chu, A., Attié, J.-L., Giglio, L., Wood, S. W., Haywood, J., Deeter, M. N., Massie, S. T., Ziskin, D. C., and Drummond J. R.: Satellite-observed pollution from Southern Hemisphere biomass burning, J. Geophys. Res.-Atmos., 111, D14312, doi:10.1029/2005JD006655, 2006.

Emmons, L. K., Deeter, M. N., Gille, J. C., Edwards, D. P., Attié, J.-L., Warner, J., Ziskin, D., Francis, G., Khattatov, B., Yudin, V., Lamarque, J.-F., Ho, S.-P., Mao, D., Chen, J. S., Drummond, J., Novelli, P., Sachse, G., Coffey, M. T., Hannigan, J. W., Gerbig, C., Kawakami, S., Kondo, Y., Takegawa, N., Schlager, H., Baehr, J., and Ziereis, H.: Validation of Measurements of Pollution in the Troposphere (MOPITT) CO retrievals with aircraft in situ profiles, J. Geophys. Res.-Atmos., 109, D03309, doi:10.1029/2003JD004101, 2004.

Filipiak, M. J., Harwood, R. S., Jiang, J. H., Li, Q., Livesey, N. J., Manney, G. L., Read, W. G., Schwartz, M. J., Waters, J. W., and Wu, D. L.: Carbon monoxide measured by EOS MLS on Aura: First results, Geophys. Res. Lett., 32, 14, L14825, doi:10.1029/2005GL022765, 2005.

Fischer, H., Birk, M., Blom, C., Carli, B., Carlotti, M., von Clarmann, T., Delbouille, L., Dudhia, A., Ehhalt, D., Endemann, M., Flaud, J. M., Gessner, R., Kleinert, A., Koopman, R., Langen, J., López-Puertas, M., Mosner, P., Nett, H., Oelhaf, H., Perron, G., Remedios, J., Ridolfi, M., Stiller, G., and Zander, R.: MIPAS: an instrument for atmospheric and climate research, Atmos. Chem. Phys., 8, 2151-2188, 2008,

http://www.atmos-chem-phys.net/8/2151/2008/.

Folkins, I., Bernath, P., Boone, C., Lesins, G., Livesey, N., Thompson, A. M., Walker, K., and Witte, J. C.: Seasonal cycles of $\mathrm{O}_{3}$, $\mathrm{CO}$, and convective outflow at the tropical tropopause, Geophys. Res. Lett., 33, 16, L16802, doi:10.1029/2006GL026602, 2006.

Frankenberg, C., Platt, U., and Wagner, T.: Retrieval of CO from SCIAMACHY onboard ENVISAT: detection of strongly polluted areas and seasonal patterns in global $\mathrm{CO}$ abundances, Atmos. Chem. Phys., 5, 1639-1644, 2005,

http://www.atmos-chem-phys.net/5/1639/2005/.

Frisk, U., Hagström, M., Ala-Laurinaho, J., Andersson, S., Berges, J.-C., Chabaud, J.-P., Dahlgren, M., Emrich, A., Florén, H.-G., Florin, G., Fredrixon, M., Gaier, T., Haas, R., Hirvonen, T., Hjalmarsson, Å., Jakobsson, B., Jukkala, P., Kildal, P. S., Kollberg, E., Lassing, J., Lecacheux, A., Lehikoinen, P., Lehto, A., Mallat, J., Marty, C., Michet, D., Narbonne, J., Nexon, M., Olberg, M., Olofsson, O. H., Olofsson, G., Origné, A., Petersson, M., Piironen, P., Pons, R., Pouliquen, D., Ristocelli, I., Rosolen, C., Rouaix, G., Räisänen, A. V., Serra, G., Sjöberg, G., Stenmark, L., Torchinsky, S., Tuovinen, J., Ullberg, C., Vinterhav, E., Wadefalk, N., Zirath, H., Zimmermann, P., and Zimmermann, R.: The Odin satellite - I. Radiometer design and test, Astron. Astrophys., 402, 3, 27-34, 2003.

Froidevaux, L., Livesey, N. J., Read, W. G., Jiang, Y. B., Jimenez, C. J., Filipiak, M. J., Schwartz, M. J., Santee, M. L., Pumphrey, H. C., Jiang, J. H., Wu, D. L., Manney, G. L., Drouin, B. J., Waters, J. W., Fetzer, E. J., Bernath, P. F., Boone, C. D., Walker, K. A., Jucks, K. W., Toon, G. C., Margitan, J. J., Sen, B., Webster, C. R., Christensen, L. E., Elkins, J. W., Atlas, E., Lueb, R. A., and Hendershot, R.: Early validation analyses of atmospheric profiles from EOS MLS on the Aura satellite, IEEE T. Geosci. Remote, 44, 5, 2006.
Funke, B., López-Puertas, M., Bermejo-Pantaleón, D., von Clarmann, T., Stiller, G. P., Höpfner, M., Grabowski, U., and Kaufmann, M.: Analysis of nonlocal thermodynamic equilibrium $\mathrm{CO} 4.7 \mu \mathrm{m}$ fundamental, isotopic, and hot band emissions measured by the Michelson Interferometer for Passive Atmospheric Sounding on Envisat, J. Geophys. Res., 112, D11305, doi:10.1029/2006JD007933, 2007.

Goldman, A., Paton-Walsh, C., Bell, W., Toon, G. C., Blavier, J. F., Sen, B., Coffey, M. T., Hannigan, J. W., Mankin W. G.: Network for the Detection of Stratospheric Change Fourier transform infrared intercomparison at Table Mountain Facility, November 1996, J. Geophys. Res.-Atmos., 104(D23), 30 481-30 503, 1999.

Hase, F., Hannigan, J. W., Coffey, M. T., Goldman, A., Höpfner, M., Jones, N. J., Rinsland, C. P., and Wood, S. W.: Intercomparison of retrieval codes used for the analysis of high-resolution, ground-based FTIR measurements, J. Quant. Spectrosc. Ra., 87, 25-52, 2004.

Hauchecorne, A., Godin, S., Marchand, M., Heese, B., and Souprayen, C.: Quantification of the transport of chemical constituents from the polar vortex to midlatitudes in the lower stratosphere using the high-resolution advection model MIMOSA and effective diffusivity, J. Geophys. Res., 107(D20), 8289, doi:10.1029/2001JD000491, 2002.

Hegglin, M. I., Boone, C. D., Manney, G. L., Shepherd, T. G., Walker, K. A., Bernath, P. F., Daffer, W. H., Hoor, P., and Schiller, C.: Validation of ACE-FTS satellite data in the upper troposphere/lower stratosphere (UTLS) using non-coincident measurements, Atmos. Chem. Phys., 8, 1483-1499, 2008, http://www.atmos-chem-phys.net/8/1483/2008/.

Jin, J. J., Semeniuk, K., Jonsson, A. I., Beagley, S. R., McConnell, J. C., Boone, C. D., Walker, K. A., Bernath, P. F., Rinsland, C. P., Dupuy, E., Ricaud, P., de La Noë, J., Urban, J., and Murtagh, D.: Co-located ACE-FTS and Odin/SMR stratospheric-mesospheric CO 2004 measurements and comparison with a GCM, Geophys. Res. Lett., 32, L15S03, doi:10.1029/2005GL022433, 2005.

Jones, N. B., Kasai, Y., Dupuy, E., Murayama, Y., Barret, B., Sinnhuber, M., Kagawa, A., Koshiro, T., Urban, J., Ricaud, P., and Murtagh, D.: Stratomesospheric CO measured by a groundbased Fourier Transform Spectrometer over Poker Flat, Alaska: Comparisons with Odin/SMR and a 2-D model, J. Geophys. Res., 112, D20303, doi:10.1029/2006JD007916, 2007.

Kasai, Y. J., Kagawa, A., Jones, N., Fujiwara, A., Seki, K., Murayama, Y., and Murcray, F.: Seasonal Variations of CO and $\mathrm{HCN}$ in the Troposphere Measured by Solar Absorption Spectroscopy Over Poker Flat, Alaska, Geophys. Res. Lett., 32, L19812, doi:10.1029/2005GL022826, 2005a.

Kasai, Y. J., Koshiro, T., Endo, M., Jones, N. B., and Murayama, Y.: Ground-based measurement of strato-mesospheric $\mathrm{CO}$ by a FTIR spectrometer over Poker Flat, Alaska, Adv. Space. Res., 35(11), 2024-2030, doi:10.1016/j.asr.2005.04.099, 2005b.

Kurylo, M. J.: Network for the detection of stratospheric change (NDSC), Proceedings of SPIE The International Society for Optical Engineering, Remote Sensing of Atmospheric Chemistry, 1491, 168-174, 1991.

Livesey, N. J., Snyder, W. V., Read, W. R., and Wagner, P. A.: Retrieval algorithms for the EOS Microwave Limb Sounder (MLS) instrument, IEEE T. Geosci. Remote, 44, 5, 1144-1155, 2006.

Livesey, N. J., Filipiak, M. J., Froidevaux, L., Read, W. R., Lambet, A., Santee, M. L., Jiang, J. H., Pumphrey, H. C., Waters, J. W., 
Cofield, R. E., Cuddy, D. T., Daffer, W. H., Drouin, B. J., Fuller, R. A., Jarnot, R. F., Jiang, Y. B., Knosp, B. W., Li, Q. B., Perun, V. S., Schwartz, M. J., Snyder, W. V., Stek, P. C., Thurstans, R. P., Wagner, P. A., Avery, M., Browell, E. V., Cammas, J. P., Christensen, L. E., Diskin, G. S., Loewenstein, M., Lopez, J. D., Nedelec, P., Osterman, G. B., Sachse, G. W., and Webster, C. R.: Validation of Aura Microwave Limb Sounder $\mathrm{O}_{3}$ and $\mathrm{CO}$ observations in the upper troposphere and lower stratosphere, J. Geophys. Res., 113, D15S02, doi:10.1029/2007JD008805, 2008.

Logan, J., Prather, M. J., Wofsy, S. C., and McElroy, M. B.: Tropospheric chemistry: A global perspective, J. Geophys. Res., 86, 7210-7254, 1981.

Luo, M., Rinsland, C. P., Rodgers, C. D., Logan, J. A., Worden, H., Kulawik, S., Eldering, A., Goldman, A., Shephard, M. W., Gunson, M., and Lampel, M.: Comparison of carbon monoxide measurements by TES and MOPITT: Influence of a priori data and instrument characteristics on nadir atmospheric species retrievals, J. Geophys. Res., 112, D09303, doi:10.1029/2006JD007663, 2007a.

Luo, M., Rinsland, C., Fisher, B., Sachse, G., Diskin, G., Logan, J., Worden, H., Kulawik, S., Osterman, G., Eldering, A., Herman, R., and Shephard, M.: TES carbon monoxide validation with DACOM aircraft measurements during INTEX-B 2006, J. Geophys. Res., 112, D24S48, doi:10.1029/2007JD008803, 2007b.

Manney, G. L., Daffer, W. H., Strawbridge, K. B., Walker, K. A., Boone, C. D., Bernath, P. F., Kerzenmacher, T., Schwartz, M. J., Strong, K., Sica, R. J., Krüger, K., Pumphrey, H. C., Froidevaux, L., Lambert, A., Santee, M. L., Livesey, N. J., Remsberg, E. E., Mlynczak, M. G., and Russell III, J. R.: The high Arctic in extreme winters: vortex, temperature, and MLS and ACE-FTS trace gas evolution, Atmos. Chem. Phys., 8, 505-522, 2008, http://www.atmos-chem-phys.net/8/505/2008/.

Marenco, A., Thouret, V., Nédélec, P., Smit, H., Helten, M., Kley, D., Karcher, F., Simon, P., Law, K., Pyle, J., Poschmann, G., Von Wrede, R., Hume, C., and Cook, T.: Measurement of ozone and water vapour by Airbus in-service aircraft: The MOZAIC airborne program, An overview, J. Geophys. Res., 103, D19, $25631-25642,1998$.

Moreau, G., Robert, C., Catoire, V., Chartier, M., Camy-Peyret, C., Huret, N., Pirre, M., Pomathiod, L., and Chalumeau, G.: SPIRALE: a multispecies in situ balloon-borne instrument with six tunable diode laser spectrometers, Appl. Optics, 44, 28, 59725989, 2005.

Murtagh, D. P., Frisk, U., Merino, F., Ridal, M., Jonsson, A., Stegman, J., Witt, G., Eriksson, P., Jiménez, C., Mégie, G., de la Noë, J., Ricaud, P., Baron, P., Pardo, J. R., Hauchecorne, A., Llewellyn, E. J., Degenstein, D. A., Gattinger, R. L., Lloyd, N. D., Evans, W. F. J., McDade, I. C., Haley, C. S., Sioris, C., von Savigny, C., Solheim, B. H., McConnell, J. C., Strong, K., Richardson, E. H., Leppelmeier, G. W., Kyrölä, E., Auvinen, H., and Oikarinen, L.: An overview of the Odin atmospheric mission, Can. J. Phys., 80, 309-319, 2002.

Nedelec, P., Cammas, J. P., Thouret, V., Athier, G., Cousin, J. M., Legrand, C., Abonnel, C., Lecoeur, F., Cayez, G., and Marizy, C.: An improved infra-red carbon monoxide analyser for routine measurements aboard commercial Airbus aircraft: Technical validation and first scientific results of the MOZAIC III program, Atmos. Chem. Phys., 3, 1551-1564, 2003, http://www.atmos-chem-phys.net/3/1551/2003/.
Nedelec, P., Thouret, V., Brioude, J., Sauvage, B., Cammas, J.-P., and Stohl, A.: Extreme CO concentrations in the upper troposphere over northeast Asia in June 2003 from the in situ MOZAIC aircraft data, Geophys. Res. Lett., 32, L14807, doi:10.1029/2005GL023141, 2005.

Notholt, J., Kuang, Z., Rinsland, C. P., Toon, G. C., Rex, M., Jones, N., Albrecht, T., Deckelmann, H., Krieg, J., Weinzierl, C., Bingemer, H., Weller, R., Schrems, O., Science, 300, 307-310, 2003.

Park, M., Randel, W. J., Emmons, L. K., Bernath, P. F., Walker, K. A, and Boone, C. D.: Chemical isolation in the Asian monsoon anticyclone observed in Atmospheric Chemistry Experiment (ACE-FTS) data, Atmos. Chem. Phys., 8, 757-764, 2008, http://www.atmos-chem-phys.net/8/757/2008/.

Paton-Walsh, C., Bell, W., Gardiner, T., Swann, N., Woods, P., Notholt, J., Schutt, H., Galle, B., Arlander, W., and Mellqvist, J.: An uncertainty budget for ground-based Fourier transform infrared column measurements of $\mathrm{HCl}, \mathrm{HF}, \mathrm{N}_{2} \mathrm{O}$, and $\mathrm{HNO}_{3}$, deduced from results of side-by-side instrument intercomparisons, J. Geophys. Res., 102 , 867-887, 1997.

Pougatchev, N. S. and Rinsland, C. P.: Spectroscopic study of the seasonal variation of carbon monoxide vertical distribution above Kitt Peak, J. Geophys. Res., 100, 1409-1416, 1995.

Pumphrey, H. C., Filipiak, M. J., Livesey, N. J., Schwartz, M. J., Boone, C., Walker, K. A., Bernath, P., Ricaud, P., Barret, B., Clerbaux, C., Jarnot, R. F., Manney, G. L., and Waters, J. W.: Validation of middle-atmosphere carbon monoxide retrievals from Microwave Limb Sounder on Aura, J. Geophys. Res., 112, D24S38, doi:10.1029/2007JD008723, 2007.

Ricaud, P., Barret, B., Attié, J.-L., Le Flochmoën, E., Motte, E., Teyssèdre, H., Peuch, V.-H., Livesey, N., Lambert, A., Pommereau, J.-P.: Impact of land convection on tropospherestratosphere exchange in the tropics, Atmos. Chem. Phys., 7, 5639-5657, 2007, http://www.atmos-chem-phys.net/7/5639/2007/.

Rinsland, C. P., Jones, N. B., Connor, B. J., Logan, J. A., Pougatchev, N. S., Goldman, A., Murcray, F. J., Stephen, T. M., Pine, A. S., Zander, R., Mahieu, E., and Demoulin, P.: Northern and southern hemisphere ground-based infrared spectroscopic measurements of tropospheric carbon monoxide and ethane, J. Geophys. Res., 103, 28 197-28 217, 1998.

Rinsland, C. P., Mahieu, E., Zander, R., Demoulin, P., Forrer, J., and Buchmann, B.: Free tropospheric $\mathrm{CO}, \mathrm{C}_{2} \mathrm{H}_{6}$ and $\mathrm{HCN}$ above central Europe : recent measurements from the Jungfraujoch station including the detection of elevated columns during 1998, J. Geophys. Res., 105, 24 235-24 249, 2000.

Rinsland, C. P., Dufour, G., Boone, C. D., Bernath, P. F., and Chiou, L.: Atmospheric Chemistry Experiment (ACE) measurements of elevated Southern Hemisphere upper tropospheric $\mathrm{CO}$, $\mathrm{C}_{2} \mathrm{H}_{6}, \mathrm{HCN}$, and $\mathrm{C}_{2} \mathrm{H}_{2}$ mixing ratios from biomass burning emissions and long-range transport, Geophys. Res. Lett., 32, L20803, doi:10.1029/2005GL024214, 2005.

Rinsland, C. P., Luo, M., Logan, J. A., Beer, R., Worden, H., Kulawik, S. S., Rider, D., Osterman, G., Gunson, M., Eldering, A., Goldman, A., Shephard, M., Clough, S. A., Rodgers, C., Lampel, M., and Chiou, L.: Nadir measurements of carbon monoxide (CO) distributions by the tropospheric emission spectrometer instrument onboard the Aura spacecraft: Overview of analysis approach and examples of initial results, Geophys. Res. Lett., 33, L22806, doi:10.1029/2006GL027000, 2006a. 
Rinsland, C. P., Boone, C. D., Bernath, P. F., Mahieu, E., Zander, R., Dufour, G., Clerbaux, C., Turquety, S., Chiou, L., McConnell, J. C., Neary, L., and Kaminski, J. W.: First space-based observations of formic acid $(\mathrm{HCOOH})$ : Atmospheric Chemistry Experiment austral spring 2004 and 2005 Southern Hemisphere tropical-mid-latitude upper tropospheric measurements, Geophys. Res. Lett., 33, L23804, doi:10.1029/2006GL027128, 2006 b.

Rinsland, C. P., Coheur, P. F., Herbin, H., Clerbaux, C., Boone, C., Bernath, P., and Chiou, L. S.: Detection of elevated tropospheric $\mathrm{H}_{2} \mathrm{O}_{2}$ (hydrogen peroxide) mixing ratios in ACE (atmospheric chemistry experiment) subtropical infrared solar occultation spectra, J. Quant. Spectrosc. Ra., 107(2), 340-348, doi:10.1016/j.jqsrt.2007.02.009, 2007a.

Rinsland, C. P., Dufour, G., Boone, C. D., Bernath, P. F., Chiou, L. Coheur, P.-F., Turquety, S., and Clerbaux, C.: Satellite boreal measurements over Alaska and Canada during June-July 2004: Simultaneous measurements of upper tropospheric CO, $\mathrm{C}_{2} \mathrm{H}_{6}, \mathrm{HCN}, \mathrm{CH}_{3} \mathrm{Cl}, \mathrm{CH}_{4}, \mathrm{C}_{2} \mathrm{H}_{2}, \mathrm{CH}_{3} \mathrm{OH}, \mathrm{HCOOH}, \mathrm{OCS}$, and $\mathrm{SF}_{6}$ mixing ratios, Global Biogeochem. Cy., 21, GB3008, doi:10.1029/2006GB002795, 2007b.

Rinsland, C. P., Luo, M., Shephard, M. W., Clerbaux, C., Boone, C. D., Bernath, P. F., Chiou, L. S., and Coheur, P.-F.: Tropospheric Emission Spectrometer (TES) and Atmospheric Chemistry Experiment (ACE) measurements of tropospheric chemistry in tropical southeast Asia during a moderate El Niño, in 2006, J. Quant. Spectrosc. Ra., in press, doi:10.1016/j.jqsrt.2007.12.020, 2008.

Rodgers, C. D.: Inverse methods for atmospheric sounding : theory and practice, Ser. Atmos. Oceanic Planet. Phys., 2, World Sci., Hackensack, N. J., 2000.

Rodgers, C. D. and Connor, B. J.: Intercomparison of remote sounding instruments, J. Geophys. Res., 108(D3), 4116, doi:10.1029/2002JD002299, 2003.

Rothman, L. S., Jacquemart, D., Barbe, A., Benner, D. C., Birk, M., Brown, Jr. L. R., Chackerian, C., Chance, K., Coudert, L. H., Carleer, M. R., Dana, V., Devi, V. M., Flaud, J.-M., Gamache, R. R., Goldman, A., Hartmann, J.-M., Jucks, K. W., Maki, A. G., Mandin, J.-Y., Massie, S. T., Orphal, J., Perrin, A., Rinsland, C. P., Smith, M. A. H., Tennyson, J., Tolchenov, R. N., Toth, R. A., Vander Auwera, J., Varanasi, P., and Wagner, G.: The HITRAN 2004 molecular spectroscopic database, J. Quant. Spectosc. Rad., 96, 139-204, 2005.

Schneider, M., Blumenstock, T., Chipperfield, M., Hase, F., Kouker, W., Reddmann, T., Ruhnke, R., Cuevas, E., and Fischer, H.: Subtropical trace gas profiles determined by ground-based FTIR spectroscopy at Izaña $\left(28^{\circ} \mathrm{N}, 16^{\circ} \mathrm{W}\right)$ : Five year record, error analysis, and comparison with 3D-CTMs, Atmos. Chem. Phys., 5, 153-167, 2005,

http://www.atmos-chem-phys.net/5/153/2005/.

Schoeberl, M. R., Douglass, A. R., Hilsenrath, E., Bhartia, P. K., Barnett, J., Beer, R., Waters, J., Gunson, M., Froidevaux, L., Gille, J., Levelt, P. F., and DeCola, P.: Overview of the EOS Aura mission, IEEE T. Geosci. Remote, 44, 5, 1066-1074, 2006.

Senten, C., De Mazière, M., Dils, B., Hermans, C., Kruglanski, M., Neefs, E., Scolas, F., Vandaele, A. C., Vanhaelewyn, G., Vigouroux, C., Carleer, M., Coheur, P. F., Fally, S., Barret, B., Baray, J. L., Delmas, R., Leveau, J., Metzger, J. M., Mahieu, E., Boone, C., Walker, K. A., Bernath, P. F., and Strong, K.: Technical Note: New ground-based FTIR measurements at Ile de La
Réunion: observations, error analysis, and comparisons with independent data, Atmos. Chem. Phys. Discuss., 8, 827-891, 2008, http://www.atmos-chem-phys-discuss.net/8/827/2008/.

Solomon, S., Garcia, R. R., Olivero, J. J., Bevilacqua, R. M., Schwartz, P. R., Clancy, R. T., and Muhleman, D. O.: Photochemistry and transport of carbon monoxide in the middle atmosphere, J. Atmos. Sci., 42, 1072-1083, 1985.

Sussmann, R. and Buchwitz M.: Initial validation of ENVISAT/SCIAMACHY columnar CO by FTIR profile retrievals at the Ground-Truthing Station Zugspitze, Atmos. Chem. Phys., 5, 1497-1503, 2005,

http://www.atmos-chem-phys.net/5/1497/2005/.

Sussmann, R. and Borsdorff, T.: Technical note: Interference errors in infrared remote sounding of the atmosphere, Atmos. Chem. Phys., 7, 3537-3557, 2007,

http://www.atmos-chem-phys.net/7/3537/2007/.

Thouret, V., Marenco, A., Logan, J. A., Nédélec, P., and Grouhel C.: Comparisons of ozone measurements from the MOZAIC airborne program and the ozone sounding network at eight locations, J. Geophys. Res., 103(D19), 25695-25720, 1998.

Turquety, S., Hadji-Lazaro, J., Clerbaux, C., Hauglustaine, D. A., Clough, S. A., Cassé, V., Schlüssel, P., and Mégie, G.: Operational trace gas retrieval algorithm for the Infrared Atmospheric Sounding Interferometer, J. Geophys. Res., 109, D21301, doi:10.1029/2004JD004821, 2004.

Turquety, S., Clerbaux, C., Law, K., Coheur, P.-F., Cozic, A., Szopa, S., Hauglustaine, D. A., Hadji-Lazaro, J., Gloudemans, A. M. S., Schrijver, H., Boone, C. D., Bernath, P. F., and Edwards, D. P.: CO emission and export from Asia: an analysis combining complementary satellite measurements (MOPITT, SCIAMACHY and ACE-FTS) with global modeling, Atmos. Chem. Phys. Discuss., 8, 1709-1755, 2008,

http://www.atmos-chem-phys-discuss.net/8/1709/2008/.

Velazco, V., Wood, S. W., Sinnhuber, M., Kramer, I., Jones, N. B., Kasai, Y., Notholt, J., Warneke, T., Blumenstock, T., Hase, F., Murcray, F. J., and Schrems, O.: Annual variation and global distribution of strato-mesospheric carbon monoxide measured by ground-based Fourier transform infrared spectroscopy, Atmos. Chem. Phys., 7, 1305-1312, 2007,

http://www.atmos-chem-phys.net/7/1305/2007/.

von Clarmann, T., Glatthor, N., Grabowski, U., Höpfner, M., Kellmann, S., Kiefer, M., Linden, A., Mengistu Tsidu, G., Milz, M., Steck, T., Stiller, G. P., Wang, D. Y., Fischer, H., Funke, B., Gil-López, S., and López-Puertas, M.: Retrieval of temperature and tangent altitude pointing from limb emission spectra recorded from space by the Michelson Interferometer for Passive Atmospheric Sounding (MIPAS), J. Geophys. Res., 108, 4736, doi10.1029/2003JD003602, 2003.

Warner, J., McCourt Comer, M., Barnet, C. D., McMillan, W. W., Wolf, W., Maddy, E., and Sachse, G.: A comparison of satellite tropospheric carbon monoxide measurements from AIRS and MOPITT during INTEX-A, J. Geophys. Res., 112, D12S17, doi:10.1029/2006JD007925, 2007.

Waters, J. W.: The Earth Observing System Microwave Limb Sounder (EOS MLS) on the Aura satellite, IEEE T. Geosci. Remote, 44, 5, 1106-1121, 2006.

Wiacek, A., Taylor, J. R., Strong, K., Saari, R., Kerzenmacher, T., Jones, N. B., and Griffith, D. W. T.: Ground-Based Solar Absorption FTIR Spectroscopy: Characterization of Retrievals and 
First Results from a Novel Optical Design Instrument at a New NDACC Complementary Station., J. Atmos. Oceanic Technology, 24, 3, 432-448, 2007.

Yurganov, L. N., Blumenstock, T., Grechko, E. I., Hase, F., Hyer, E. J., Kasischke, E. S., Koike, M., Kondo, Y., Kramer, I., Leung, F.Y., Mahieu, E., Mellqvist, J., Notholt, J., Novelli, P. C., Rinsland, C. P., Scheel, H. E., Schulz, A., Strandberg, A., Sussmann, R., Tanimoto, H., Velazco, V., Zander, R., Zhao, Y.: A quantitative assessment of the 1998 carbon monoxide emission anomaly in the Northern Hemisphere based on total column and surface concentration measurements, J. Geophys. Res., 109(D15), D15305, 2004.
Yurganov, L. N., Duchatelet, P., Dzhola, A. V., Edwards, D. P., Hase, F., Kramer, I., Mahieu, E., Mellqvist, J., Notholt, J., Novelli, P. C., Scheel, H.-E., Schneider, M., Schulz, A., Strandberg, A., Sussmann, R., Tanimoto, H., Velazko, V., Drummond, J. R., and Gille, J. C.: Increased Northern Hemispheric CO burden in the troposphere in 2002 and 2003 detected from the ground and from a satellite, Atmos. Chem. Phys., 5, 563-573, 2005, http://www.atmos-chem-phys.net/5/563/2005/. 